\title{
Practice-oriented buildability criteria for developing 3D-printable concretes in the context of digital construction
}

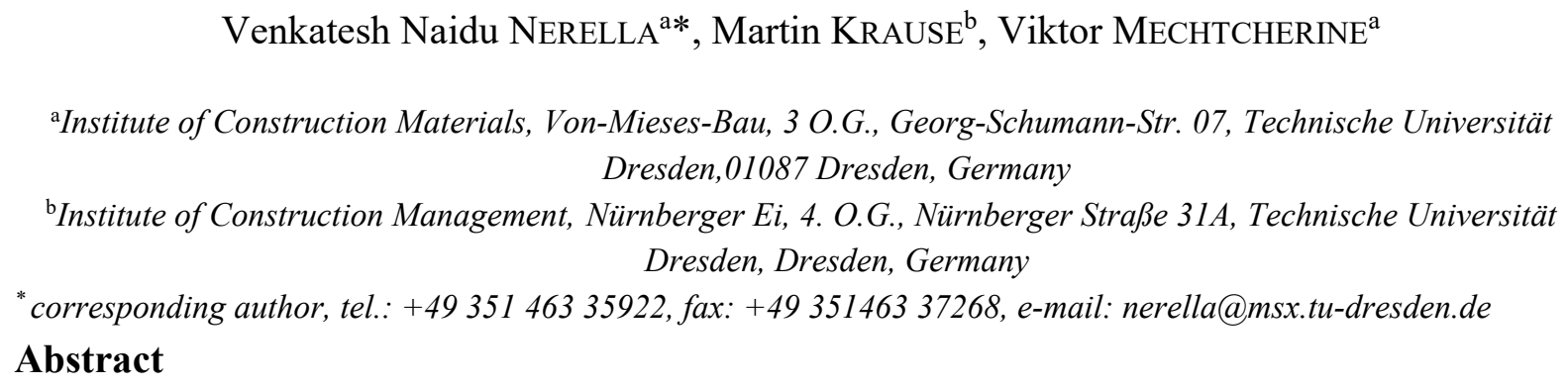

Buildability, i.e. the ability of a deposited material bulk to retain its dimmensions under increasing load, is an inherent prerequisite for formwork-free digital construction (DC). Since DC processes are relatively new, no standard methods of characterization are available yet. The paper at hand presents practice-oriented buildabilty criteria by taking various process parameters and construction costs into consideration. In doing so, direct links between laboratory buildability tests and target applications are established. A systematic basis for calculating the time interval (TI) to be followed during laboratory testing is proposed for the full-width printing (FWP) and filament printing (FP) processes. The proposed approach is validated by applying it to a high-strength, printable, fine-grained concrete. Comparative analyses of FWP and FP revealed that to test the buildability of a material for FP processes, higher velocities of the printhead should be established for laboratory tests in comparison to those needed for FWP process, providing for equal construction rates.

\section{Highlights:}

1. Practice-oriented criteria for characterizing buildability are proposed.

2. The applicability of the model in quantifying the economic viability of 3D-printing is demonstrated.

3. Specimen height and time interval are specified as parameters for buildability tests on printable concretes.

4. Proposed buildability criteria are validated by tests on a printable concrete.

5. Variations regarding buildability test specifications for full-width and filament printing techniques are described.

Keywords: Digital Construction; 3D-concrete-printing; buildabiltiy, additive manufacturing.

\section{Introduction and definitions}

\subsection{Digital construction and requirements for fresh concrete}

The processing of cementitious materials is the technological core of modern construction. In recent years numerous new construction techniques based on digitalization and automation have been developed; see e.g. [1-6]. These modern construction processes can be referred to with the generic process title Digital Construction (DC), which denotes automated additive (or generative) construction with cementitious materials. DC opens a multitude of opportunities and technological advancements: 
- no need for formwork, enabling high geometric flexibility $[6,7]$,

- additional functionalities $[1,2,6]$,

- considerable reductions in time and cost $[5,8]$,

- low dependency on skilled labor, etc.

However, the major significance and revolutionary potential of DC reveal themselves in the context of Construction Industry 4.0 since it represents a logical, decisive step arising from the already well-developed tools of digital design and planning (CAD, BIM, etc.) towards digital manufacturing, thus making construction a fully digitalized, seamless process.

Two common digital construction techniques are selective material deposition by extrusion and selective binding. The working principles and details of these two approaches are described in more detail in, for example, $[3,5]$, while Figure 1 presents examples of structures produced using these techniques. When it comes to large-scale and on-site applications, extrusion-based techniques appear more suitable; see Figure 1a. The dimensions of the printing device for selective binding techniques must be bigger than those of the target structure $[3,5,9]$. This is not the case for many extrusion-based DC technologies, as the examples of CONPrint3D [5] and Apis Cor [10] demonstrate. Furthermore, in the case of selective material deposition by extrusion, material is delivered only where it is needed permanently and should, therefore, be sufficiently "buildable". In contrast, in selective binding techniques the support material surrounding the material to be bonded is crucial to keeping its shape while it is still in plastic state. The need for support material has both positive and negative consequences: structures of any geometrical shape can be produced (positive); see Figure 1b, but all the non-bonded material must eventually be removed (negative). Thus, at this stage the practical application of selective binding techniques seems to be feasible for off-site production of complex elements having relatively small dimensions only. This is one reason why this article focuses exclusively on extrusion-based techniques. Another reason is that due to the mandatory presence of support material, buildability is not really a challenge in the context of selective binding technology.

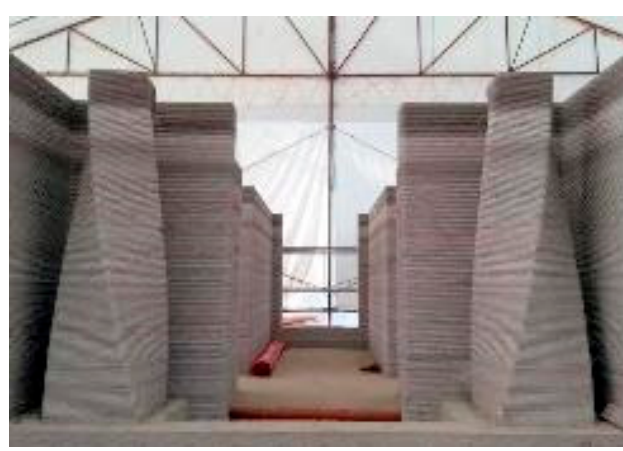

a)

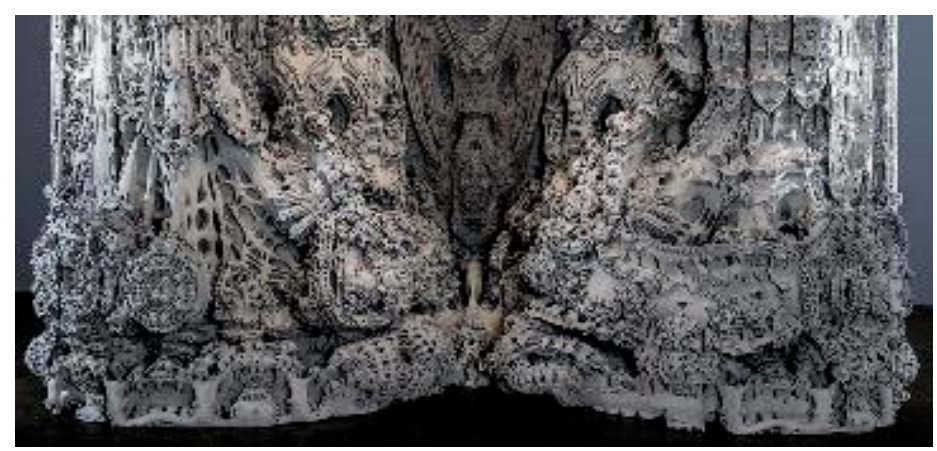

b)
66

67

68

69

70

Figure 1. Examples of digital construction approaches: a) structural elements produced on-site using selective material deposition by extrusion [4], b) complex structure of Digital Grotesque II produced in a stationary 3Dprinter using selective binding technique [11]

Based on layering technique, extrusion-based DC processes can be classified as full-width printing (FWP) and filament printing (FP). In FWP the breadth of the extrudate is equal to that of the target 
element, as in CONPrint3D; see Figure 2a. In case of FP the breadth of the extrudate is many times smaller than the breadth of the target element, as in Contour Crafting [1,2,4,12,13] (Figure 2b) or even more pronounced in fine filament approach called Concrete Printing $[2,14,15]$; see Figure 2c. Consequently, a cross-section of FP elements consists of outer layers (shell/mold) and inner layers or fillings.

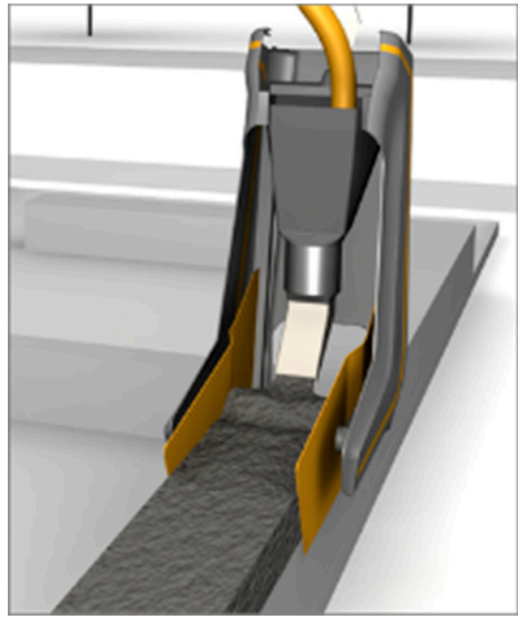

a)

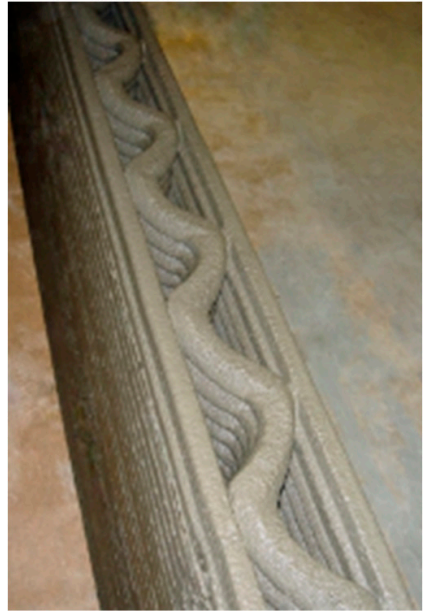

b)

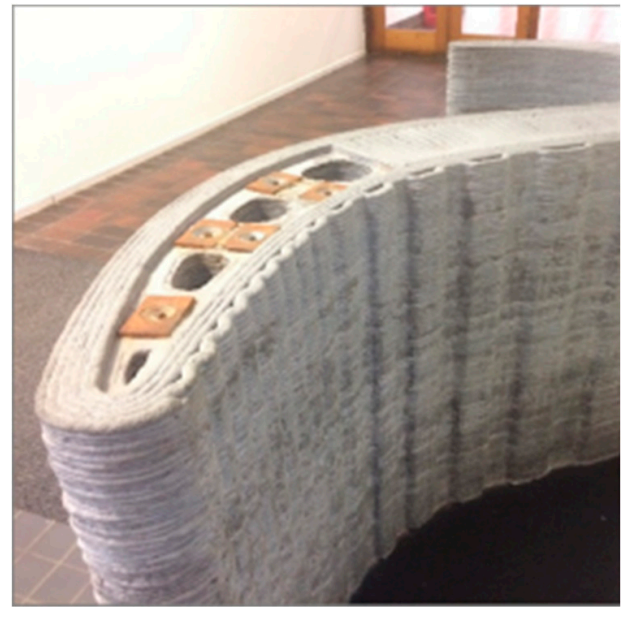

c)

Figure 2. a) CONPrint3D technology as example of full-width printing [courtesy: Chair of Construction Machines, TU Dresden], b) Contour Crafting as example of filament printing [courtesy: Contour Crafting], c) Wonder Bench at Loughborough University as example of fine filament printing (photo by V. Mechtcherine)

In terms of engineering properties, the primary requirements of cementitious materials for selective material deposition by extrusion are: 1) pumpability, 2) extrudability, and 3) buildability; see also Figure 3. Adequate pumpability should ensure the uninterrupted transportation of fresh concrete and depends on, among other parameters, the plastic viscosity of the concrete, or rather the formation of a lubricating layer [16-18]) in the first place. Extrudability refers to the ease of continuously extruding a material at a given flow rate; it depends on the rheological properties of the fresh concrete and the geometrical configuration of the extruder, or printhead. This being said, buildability, the term and the central subject of this article, is defined as the ability of an extruded material to retain its geometry (shape and size) under sustained and increasing loads. The explanation of this definition follows in Section 1.2.

As pointed out in [5], DC is a process of many dualities, e.g. the duality of pumpability and buildability since rheological properties favorable for each of these two processes differ markedly, or the duality arising while determining the 'rate of printing', incl. economic efficiency, possible formation of "cold joints", etc. From a scientific perspective the rheological properties of fresh cementitious material are the most crucial aspect of DC, since they affect not only the process parameters but also the properties of the final product. 


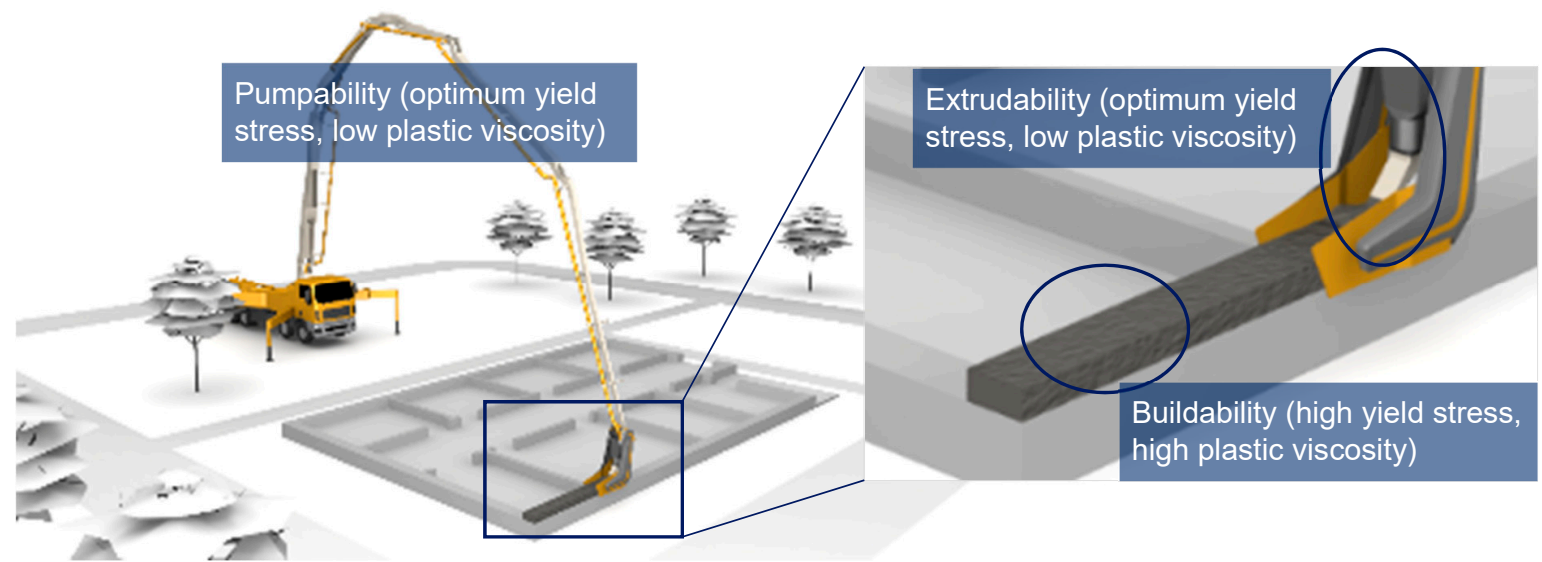

\section{Figure 3. Illustration of key properties for printable concrete on example of CONPrint $3 D$ technology (base sketches} are of courtesy: Chair of Construction Machines, TU Dresden).

To fulfil the main requirements of extrusion-based DC, cementitious material should be thixotropic, quick setting, quickly hydrating to develop strength very early, and densely packed, and it should possess well controlled rheological properties such as yield stress and plastic viscosity, possibly controllable through internal or external triggers [19]. While this general approach is widely understood, many essential aspects are still under research. The open questions include the systematic choice of rheological parameters and identification of their threshold values. Most importantly, validated experimental methods are necessary to characterize and ensure the desired material properties. In their work in this connection the authors address the question of how one of the primary engineering properties of cementitious materials for DC, namely buildability, can be systematically characterized. Specifically addressed are the questions of what a representative piece of wall is, i.e. height, breadth to be tested in lab-scale buildability tests, and what are the time intervals to be tested in order to call a material printable are addressed.

\subsection{Buildability requirements and the problem definition}

Buildability is the ability of extruded material to retain its geometric dimensions, both shape and size, under sustained or increasing loads. It is a complex, process-specific property which depends not only on material composition, but on process parameters such as layer geometry as well; cf. Figure 2. If buildability, printing rate, printing pattern, and other related aspects are not in harmony, the 3D-printed structure will collapse; see Figure $4 \mathrm{~b}$. Buildability depends on, but is not identical to, the structural build-up of cement-based materials, and this dependence is not exclusive.

From a practical perspective, there are three primary parameters defining any buildability criteria when applied in laboratory investigations for material characterization: 1) the height of the wall to be printed, 2) the height of each layer or the total number of layers to be printed, and 3) the time interval (TI) between subsequent layers.

Since many of the properties required for 3D-printable concretes need a "perfect" balance, it is essential to consider target application at all stages of material development. The buildabilitydefining parameters mentioned above must be carefully determined, considering various theoretical and practical aspects and then applying them in testing the applicability of particular 
mixtures for target DC. 3D-printed elements should have consistent and continuous layer geometry over the entire structure. Figure 4 shows an example of printed specimens with varying numbers of layers and buildabiltiy. It is often appealing to print 10,20 or as many layers as possible and then 'designate' the material as buildable. This trivial approach neither links the material's fresh properties to the target geometry nor does it consider the economic viability of the target application. While such an approach is still useful for relative comparison of various compositions, printing an arbitrary number of layers with an arbitrary time interval $T I$ is not a reliable method in characterizing buildability. Flowable concrete with low static yield stress, extruded to wide, but thin layers using a long $T I$, will likely sustain deposition of a higher number of layers in comparison to a less flowable concrete but deposited with a much higher aspect ratio $\alpha_{L, a p p}$ of individual layers and a short $T I$; see Section 2. Further relevant parameters are economic viability and durability of the structure, both dependent on TI. Durability is a function of the quality of interlayer joints, which very importantly depends on $T I$. Thus, for buildability it is crucial to determine one criterion or several criteria based on the intended application and estimated process parameters.

In Section 2 previously proposed approaches to estimate buildability based on rheological modelling are critically presented before our own practice-oriented criteria are introduced, which define buildability in terms of target application and process parameters. The applicability of proposed criterion is demonstrated on an example DC process in Section 3, deducing preferable layer height and time interval needed as a basis for developing suitable concretes. Since buildability requirements depend not only upon the target structure but also on the applied printing approach, e.g. massive vs. 'hollow with sinusoidal cores' as seen in Figure 2, a corresponding comparative analysis is presented in Section 4.

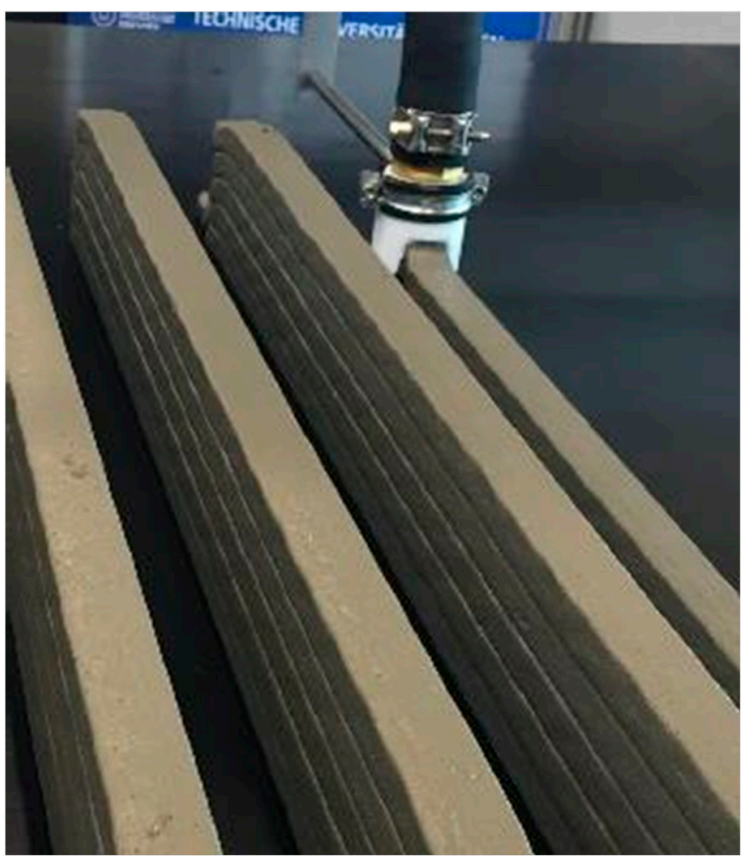

a)

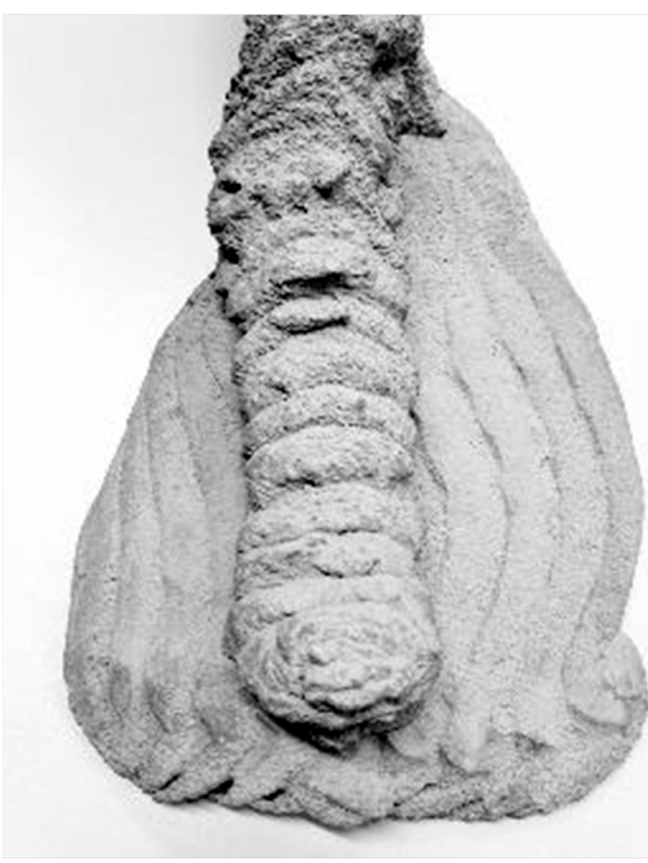

b)

Figure 4. a) 3D-printed fine-grained concrete specimens (up to five printed layers are depicted here, time interval was $30 \mathrm{~s}$ ), b) a collapsed printed specimen with buildability deficiency. 


\section{Buildability criteria considering target application}

\subsection{Previous approaches}

Buildability criteria based on fundamental rheological properties, e.g. static yield stress, and the associated changes over time are still in their genesis; it will take some years until development and validation are complete. Generic rheological models which can consider various process techniques, the shape of the extrudate, and the effects of temperature and other surrounding conditions will take even longer to be formulated and proven. All that existing criteria can predict is whether a deposited material during a time of rest $t_{\text {rest }}$ deforms or not. However, they do not consider the economic viability of the target application, meaning that even if a material is proven buildable as such at a particular printing rate, it is not known how the use of that particular material/printing rate influences the total economic viability of the target project. Hence, simple, practice-oriented, yet rational buildability-assurance criteria are necessary to accelerate the implementation of digital technologies in construction practice. One such approach is presented in the following sections.

In the limited literature on the subject of this article, three significant contributions can be identified [19-21]. In the first on-the-topic, commendable work, Perrot et al. [20] considered the following primary criterion: 'the flow resistance of a substrate-layer should always be higher than the vertical loads acting on top of it'. The researchers expressed the vertical loads in terms of printing speed and hydrostatic pressure of concrete using Eq. 1:

$\sigma_{v}=\rho \cdot g \cdot R \cdot t$

Eq. 1

where $\rho$ is the specific weight of concrete, $\mathrm{g}$ is the gravity constant, $R$ is rate of construction, and $t$ is the time of construction.

The flow resistance of the substrate-layer, expressed as time-dependent static yield stress is described by Eq. 2, Perrot's exponential evolution model for thixotropy [22]:

$\sigma_{c}(t)=\tau_{0}(t)=\alpha_{\text {geom }}\left(\tau_{0,0}+A_{\text {thix }} \cdot t_{c}\left(e^{\frac{t_{\text {rest }}}{t_{c}}}-1\right)\right)$

Eq. 2

where $\tau_{0,0}$ and $\tau_{0}(t)$ are static yield stresses of the material when resting time is zero and $t$, respectively; $A_{\text {thix }}$ is the constant rate of increase in the static yield stress; $t_{c}$ is a characteristic time after which yield stress evolution at rest becomes exponential; $\alpha_{\text {geom }}$ is a geometric factor which depends on the geometry of the deposited layer/printed element [20].

Alternatively, the resistance of a substrate-layer can be estimated using Roussel's linear evolution model for thixotropy [23]; see Eq. 3:

$\sigma_{c}(t)=\tau_{0}(t)=\alpha_{\text {geom }}\left(\tau_{0,0}+A_{\text {thix }} \cdot t_{c}\right)$

Eq. 3

Applying buildability criteria according to Perrot et al. [20] (Eq. 1) for Eqs. 2 and 3, we obtain:

$\rho \cdot g \cdot R \cdot t \leq \alpha_{\text {geom }}\left(\tau_{0,0}+A_{\text {thix }} \cdot t_{c}\left(e^{\frac{t_{\text {rest }}}{t_{c}}}-1\right)\right)$

Eq. 4

$\rho \cdot g \cdot R \cdot t \leq \alpha_{\text {geom }}\left(\tau_{0,0}+A_{\text {thix }} \cdot t_{c}\right)$

Eq. 5 
185 Finally, a critical failure time $t_{f}$ according to Perrot with Roussel' linear model [23] for thixotropy 186 is:

$187 \quad t_{f}=\frac{\tau_{0,0}}{\frac{\rho \cdot g \cdot R}{\alpha_{g e o m}}-A_{\text {thix }}}$ Eq. 6

$188 t_{f}$ predicts at what time after deposition the concrete specimen fails/fractures, if vertical load is 189 increased at rate $R$ and the material initial yield stress $\tau_{0,0}$ is evolving linearly [23] with a slope 190 Athix.

191 Similar to Perrot et al., Wangler et al. [19] rely on the relationship of flow resistance of a substrate192 layer, expressed as static yield stress, to the vertical loads acting on top of it. Wangler's model for 193 minimum time to print a layer follows Von Miese's criteria and Roussel' linear model [23] for 194 structural build-up:

$195 \quad t_{h, \min }=\frac{\rho \cdot g \cdot h}{\sqrt{3} \cdot A_{\text {thix }}}$ Eq. 7

196 In other words, the minimum time $t_{h, \min }$ for producing a layer can also be termed as the minimum 197 interval between two successive layers needed to ensure "buildability".

198 Even though both of these works above are outstanding contributions to the subject of this paper, 199 there are still a few challenges to be mastered before these criteria can become widely applicable. 200 For instance, the parameter $\alpha_{\text {geom }}$ is not generically defined yet. Perrot et al. [20] computed $\alpha_{\text {geom }}$ 201 from the squeeze flow theory of plastics [24,25]. Determining the structuration parameter $A_{\text {thix }}$ is 202 also not a trivial task. Currently there are neither standard devices nor standard protocols for 203 characterizing $A_{\text {thix }}$ of cementitious materials. Even using most modern rheometers different $A_{\text {thix }}$ 204 values may be derived for the same material when different measuring protocols are employed. 205 This implies that for the same material, different critical failure time or minimum time intervals 206 can be computed using Eq. 6 and Eq. 7, respectively.

207 Furthermore, Eq. 6 and Eq. 7 are formulae for the onset of flow/deformation. This means that even 208 if all parameters, including $\alpha_{\text {geom }}$ and $A_{\text {thix }}$, are determined precisely, the primary calculation result 209 will be whether the material will deform or not. Such a prediction naturally underestimates the 210 ability of the material to withstand applied loads. In fact, in most practical cases a perfectly rigid 211 layer is not necessary; a layer which deforms within the tolerances allowed is acceptable. An 212 equilibrium reached after few millimeters of deformation is a common possibility as observed in 213 the experiments conducted by the authors and by many other researchers as well. For the target 214 application of the CONPrint3D technology - the construction of residential buildings in Germany 215 - the DIN 18202 "Tolerances in building construction - buildings" [26] specifies the permissible 216 dimensional tolerances and deviations including the specified requirements for the flatness of the 217 wall. When translated for digital construction, i.e. stacking the layers, the DIN 18202 specifications 218 imply that deviations of up to $5 \mathrm{~mm}$ between each layer are permissible. Still further, the permitted 219 dimensional deviations from the floor plan depend on the length of the wall. For example, 220 deviations of $12 \mathrm{~mm}$ are permitted for a $3 \mathrm{~m}$ long wall. These observations, combined with 221 advantages of better inter-layer bonds and pumpability, add strength to the argument for giving 
222 priority to a material which deforms within an allowed limit, as opposed to a perfectly rigid 223 material.

224 More recently, Wolfs et al. [21] developed and validated a numerical model for predicting the 225 failure of 3D-printed concrete. Attributing early strength (0 to $90 \mathrm{~min}$ ) of printed concrete to 226 "combined inter particle friction and cohesion", they have adopted Mohr-Coulomb failure criteria, 227 also considering time-dependency [21]. This model does not require measurement of $A_{\text {thix }}$ and 228 computation of $\alpha_{\text {geom }}$ as in the above-described rheology-based approaches, and the experimental 229 validation of the numerical model showed good qualitative and acceptable quantitative 230 correlations. This approach, however, requires extensive experimental studies and, similar to 231 rheology-based approaches, high precision in execution is needed. In addition, the approach did 232 not address the economic viability of the target application. A simple, practice-oriented criterion 233 for buildability tests has yet to be reported. Note that an extensive review of buildability testing 234 approaches is not the scope of the paper at hand.

235 Process-induced changes in rheological properties is another crucial subject. For example, in the 236 case of pumping SCC, differences in values of yield stress and plastic viscosity were recorded 237 before and after pumping [28]. The variation in rheological properties may result from the "higher 238 shear rates leading to the dispersion of cement particles and depending on available residual 239 superplasticizer in the mixing water" [28]. Additional data on losses in slump, changes of air-void 240 systems, influence of pressure on rheological properties can be found in [29,30]. When it comes to 241 3D-printing based on extrusion on a laboratory scale, even though the material is generally not 242 pumped over large distances, it undergoes high shear rates and is subjected to high pressure in the 243 extruder. Therefore, the exact rheological state of the extrudate may vary depending on the specific 244 extruder and printing-circuit (mixing-transporting-extruding). If large-scale, on-site applications are realized, a pronounced influence of process/pumping on the material rheological state is to be expected. Since rheological properties are usually measured on material taken immediately after mixing, variations of these off-line measured properties in comparison to the actual extrudate rheological properties are inherent. This, however, can be solved by carrying out extensive experimental studies and by the fitting of theoretically predicted "buildability" and experimentally observed "buildability". To the best of the authors' knowledge, no such studies have been reported yet.

\subsection{Suggested buildability criteria}

253 The first step in the proposed approach is to identify and define the target application. Based on 254 the building design and project planning, a detailed printing scenario must be established. This task 255 is normally seen as part of the 'design and process' aspect of DC work flow. Generally it involves 256 'slicing' the 3D geometry, identifying optimum travel route of the printhead, and determining layer 257 breadth, height, and contours. In the case of massive full-width printing (FWP) such as with the 258 CONPrint3D approach [5], layer breadth is equal to final breadth of the wall to be printed; see 259 Figure 3. The criteria presented below are proposed for full-width layer printing. Criteria for 260 filament printing such as the case with Contour Crafting [1] are addressed in Section 4; see Figure $2612 b$. 
262 For the convenience of further discussion in this article, authors define various relevant aspect 263 ratios as listed in Table 1.

264 Table 1. Aspect ratios of various elements produced by means of digital construction

\begin{tabular}{|l|c|l|}
\hline \multirow{2}{*}{ Element } & \multicolumn{2}{|l|}{ Aspect ratio } \\
\cline { 2 - 3 } & Notation & Definition \\
\hline Target wall & $\alpha_{a p p}$ & Ratio of target wall's height $H_{a p p}$ to breadth $B_{a p p}$ \\
\hline $\begin{array}{l}\text { Experimental } \\
\text { specimen }\end{array}$ & $\alpha_{\text {exp }}$ & $\begin{array}{l}\text { Ratio of } H_{\exp } \text { to breadth } B_{\exp } \text { of the wall produced in lab } \\
\text { experiment }\end{array}$ \\
\hline Target layer & $\alpha_{L, a p p}$ & $\begin{array}{l}\text { Ratio of height } H_{L, a p p} \text { to breadth } B_{L, a p p} \text { of one layer in the } \\
\text { target wall }\end{array}$ \\
\hline Experimental layer & $\alpha_{L, \text { exp }}$ & $\begin{array}{l}\text { Ratio of height } H_{L, \text { exp }} \text { to breadth } B_{L, \text { exp }} \text { of one layer in the } \\
\text { wall produced in lab experiment }\end{array}$ \\
\hline
\end{tabular}

266 If the height and breadth of the wall to be printed (part of the target structure) are $H_{\text {app }}$ and $B_{\text {app}}$, 267 respectively, then the aspect ratio of the continuously produced "target" element whose buildability 268 has to be ensured can be expressed by Eq. 8:

$269 \alpha_{a p p}=\frac{H_{a p p}}{B_{a p p}}$

Eq. 8

270 Naturally, the most straightforward but often economically unfeasible manner in verifying 271 buildability is to produce a full-scale structure of the targeted application. Alternatively, 272 buildability can be tested by producing a scaled-down version of the target structure in a laboratory 273 with an appropriate 3D-printing device. In this case printing an arbitrary number of layers with an 274 even so arbitrary time interval $T I$ will, however, not prove a material buildable; see also Section 275 1.2. Thus, the authors propose calculating the minimum height $H_{\text {min,exp }}$ of the wall to be tested in 276 the laboratory, using the breadth of the layers printed in laboratory experiments $B_{\text {exp }}$ and target 277 structure's aspect ratio $\alpha_{a p p}$ (Eq. 8) as:

279 If the height of a single layer printed in laboratory experiments is $h_{\text {layer,exp }}$

280 the total number of layers to be printed

$281 \quad n_{\text {layers }}=\frac{H_{\min , \text { exp }}}{h_{\text {layer,exp }}}$ Eq. 10

282 Combining, Eq. 9 and Eq. 10 give:

$283 \quad n_{\text {layers }}=\frac{\alpha_{\text {app }} \cdot B_{\text {exp }}}{h_{\text {layer, } \exp }}$ Eq. 11

When downscaling the wall geometry to a laboratory specimen, the limits given by each particular concrete composition must be considered. Specifically, the maximum aggregate of mixtures poses

286 a requirement of minimum breadth and height of each single layer. Choosing the minimum 287 dimension of layer cross-section to be the trifold of the maximum aggregate size seems to be 
288 adequate here. Such a ratio ensures that no pronounced wall effects occur so that the features of the material do not change and the material can be well extruded. Further comments on downscaling, including possible changes in maximum aggregate size, follow in Section 2.3.

The next open question revolves around determining the time interval between layers $T I$, which depends on the rate of printing. Rate of printing is a very crucial parameter for formwork-free construction with time-dependent materials such as concrete. If the rate of printing is too high, the printed concrete may not have sufficient time for structural build-up [31] and hence cannot retain its shape and size. If rate of printing is too low, total construction time and costs might become unfeasible. In addition, lower construction rates give rise to so-called "cold joints", i.e. weak interface bonds between the layers. This leads to the deterioration of both mechanical properties and durability. The time interval TI to be followed in laboratory tests can be deduced directly from the target process parameters. The total travel length $L$ of the printhead can be determined from the layout/floorplan of the target application; see Figure 5. With an average (horizontal) printing velocity of $V_{D C}$, the minimum time interval between two layers can be expressed as:

$T I_{\min }=L / V_{D C}$

Eq. 12

In the first approximation $V_{D C}$ is assumed constant, not accounting for a) the acceleration and deceleration at the beginning and the end of printing one layer, respectively, and b) velocity variations when printing corners. For $T I>L / V_{D C}$, the printing process has to be halted, e.g. to account for possibly insufficient buildability of the applied material, thus leading to longer construction times and losses in efficiency. For $T I<L / V_{D C}$ concrete buildability is over-engineered, i.e. more than necessary, which may affect the interlayer bond negatively, but also poses greater challenges in meeting the requirements of pumpability and extrudability. While defining $T I$, the economic viability of the target application/project must be considered as well. The corresponding process term, the average velocity $V_{D C}$, is already addressed in Eq. 12. It is worthy of note that for a wall of given gross dimensions, the time interval $T I$ will be in the case of FP approaches higher than that for FWP approaches due to longer total travel length of the printhead. This aspect is elaborated in Section 4. For any DC approach to be economically viable, the following condition according to Eq. 13 must be fulfilled:

Costs $_{D C} \leq$ Costs $_{C C}$

Eq. 13

where, $\operatorname{Costs}_{D C}$ and $\operatorname{Costs}_{C C}$ are the respective total construction costs in the case of the DC approach chosen and in the case of current corresponding conventional construction (CC) approach, respectively. Authors have identified, as an example, replacing masonry structures for residential buildings as the strategic objective for CONPrint3D [5,8]. Therefore, in this case $\operatorname{Costs}_{C C}$ are the current total construction costs for masonry in a unit residential building.

Expressing the costs of machine and labor as cost per unit time and material costs as cost per unit volume, the total costs can be estimated by using Eq. 14:

$\left(M c C o_{D C}+L a C o_{D C}\right) \cdot t_{D C}+M t C o_{D C} \cdot v_{o l} l_{D C}+A d C o_{D C} \leq\left(M c C o_{C C}+L a C o_{C C}\right) \cdot t_{C C}+M t C o_{C C} \cdot v l_{C C}$ Eq. 14 where, $M C C o_{D C}, L a C o_{D C}$ and $M C C o_{C C}, L a C o_{C C}$ are the machinery/equipment costs and labor costs for $\mathrm{DC}$ and $\mathrm{CC}$, respectively; $M t C o_{D C}, M t C o_{C C}$ are material costs for DC and $\mathrm{CC}$, respectively; 
$A d C o_{D C}$ are additional costs added only for DC. Additional costs include, among others, costs for concrete curing (more elaborate than usual), additional testing and consulting fees that may be necessary in the case of DC. $t_{D C}$ and $t_{C C}$ are the time needed for constructing the target structure in case of DC and CC, respectively, while voldc and vol $c$ are the total volumes of material used in case of DC and $\mathrm{CC}$, respectively.

Expressing time in terms of average velocity in the case of DC and inversed construction rate $R I$ (unit: $\mathrm{h} / \mathrm{m}^{2}$ ) in the case of CC, we obtain:

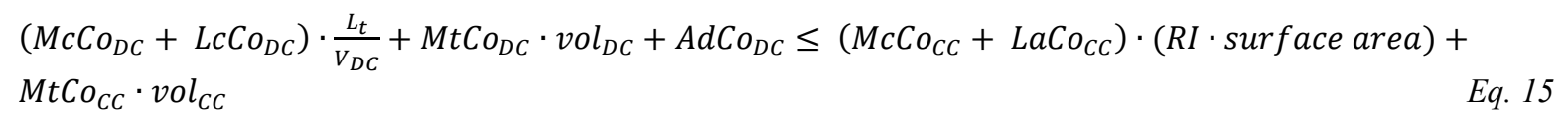

where surface area is the total "one-side" surface area of the element being constructed; $L_{t}$ is the total travel length of the printhead, which is assumed to be equal to the travel length for a single layer $L$ multiplied by the total number of layers $n_{\text {layers }}$. The traversing of the printhead without printing, for example, to move to a new printing position are not considered here as they are very specific to the target application and the related process parameters. Nevertheless, these can be added to the $L_{t}$ if known.

Additional costs $\mathrm{AdC} o_{D C}$ in the case of CONPritn3D are assumed to be a lump sum amounting to $10 \%$ of the total construction costs.

Rearranging Eq. 15, Eq. 16 for the minimum average printhead velocity for an economically viable DC application can be obtained:

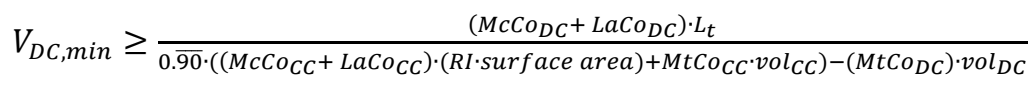

Eq. 16

Since it is known that:

- $L_{t}$ is equal to the length of the layer multiplied by the total number of layers $n_{\text {layers }}$,

- surface area is equal to the length of the layer multiplied by the height of the wall, and

- total material volume is the length multiplied by the height and breadth of the walls, Eq. 16 can be transformed to Eq. 17:

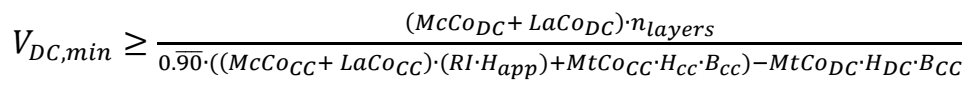

Eq. 17

where $H_{C C}, B_{C C}, H_{D C}, B_{D C}$ are the height and breadth of the walls in case of CC and DC, respectively. While $H_{C C}=H_{D C}$ is chosen here for ease of comparison, the breadth of the layers produced in DC can be smaller than that of CC. Since materials used for DC applications are often superior to masonry in terms of mechanical performance, thinner walls produced using DC can meet the same design specifications as thicker walls produced using CC. Eqs. 16 and 17 can be adapted also to other DC applications to compute a minimum average printhead velocity that should be attained to make the DC application economically viable with respect to the fabrication process as such. Certainly there are also other factors which may influence the economic feasibility to a great extent. Thus, in general the entire process from planning to actual construction should be evaluated. Specifically, the smooth transition from digital planning to digital fabrication seems to bring with it great technical and economic potential. 
364

365

366

367

368

369

370

371

372

373

374

375

376

377

378

379

380

381

382

383

384

385

386

387

388

389

390

391

392

393

394

395

396

397

398

399

400

401

402

403

404

405

\subsection{Additional comments}

The proposed approach assumes that material behavior tested on the "down-scaled specimens under laboratory conditions (lab-tests)" is representative of the material behavior in "full-scale structure in real application (full-scale)". In reality differences in material behavior as among the lab-tests and as experienced full-scale may arise, e.g. due to variation in the quality of extrusion/compaction (process-induced changes) or in the evaporation rate related to the volume of printed element.

Here it is important to emphasize that the challenge posed by some differences in lab experiments and full-scale applications is a universal issue which is not particular to buildability tests or DC in general. Taken broadly, such issues can only be resolved by full-scale tests and direct comparison, followed by error-minimization measures. The approach proposed in this paper for laboratory tests already takes into account certain considerations in mimicking conditions under full-scale application:

a) Tests are performed in-line, i.e. they are integrated in the 3D-printing process, as opposed to offline tests where material has to be collected separately and tested in a test device; thus, time-dependent influences are avoided and errors due to process induced changes are minimized.

b) Specimens are extruded using an extruder system similar to that foreseen in the prospective full-scale application, thus subjecting the tested material to similar shear history and degree of compaction.

c) The curing of laboratory specimens is adjusted to that planned for the full-scale application, indeed, if planned at all. If specific temperature, humidity, and wind conditions are expected for the full-scale application, the laboratory tests should be performed if possible under similar environmental conditions.

d) If admixtures are added in the printhead during full-scale applications, the same procedure should be implemented in the lab-scale 3D-printing.

Regarding change of scales, the authors do anticipate that the proposed approach withstand the change in scales, however, with some limitations which need further investigation. So long as the changes are only in dimensions and not in shape of the geometry, the validity of the proposed approach can be seen as convincing. Nevertheless, a correction factor may need to be introduced to take dimensional change into account. Such factors can be identified theoretically/numerically and/or with help of full-scale validation experiments. It goes without saying that in some cases (full-scale applications are large and tall structures) downscaled experiments are the only feasible option to assess the buildability.

Another issue is that downscaling is limited by minimum feasible dimensions of layer cross-section and nozzle dimensions as defined by the maximum aggregate size; this is pointed out in Section 2.2. To extend the range of downscaling, the maximum aggregate size used in mixtures for laboratory experiments may be reduced. This is an approach used sometimes in the practice of construction for various practical reasons such as the availability of appropriate testing equipment, ease of handling etc. Certainly, such change in material composition must be well thought through, and its consequences must be closely considered. However, it seems feasible to decrease maximum aggregate size for 3D-printing in laboratory since the effect of maximum aggregate size can be 
406 relatively well estimated based on available contemporary knowledge. It is known from $[19,20]$ 407 that the buildability of a printed layer can be expressed in terms of, and proportionally depends on 408 the structural build-up of concrete. MAHAUT et al. [32] related the static yield stress of cementitious 409 suspensions with coarse particles $\tau_{c}(\phi, t)$ to the static yield stress of the suspending cement paste $410 \tau_{\mathrm{c}}(0, \mathrm{t})$, to the time $t$ passed at rest, and to the coarse particle volume fraction $\phi$; see Eq. 19 . They 411 suggested that the presence of $\phi$, the volume fraction of coarse particles in a cement paste, will 412 magnify its static yield stress as a function of the volume fraction of coarse particles $g(\phi)$.

$413 \tau_{c}(\phi, t)=\tau_{c}(0, t) g(\phi)$ Eq. 18

$414 g(\phi)=\sqrt{(1-\phi)\left(1-\phi / \phi_{m}\right)^{-2.5 \phi_{m}}}$ Eq. 19

415 where $\phi_{m}$ is the maximum volume fraction.

416 In addition Mahaut et al. [32] postulated that "the structuration rate $A_{\text {thix }}$ has the same dependence 417 on the coarse particle volume fraction as the yield stress". Similar models for relating properties 418 of a suspension to suspending paste are presented and discussed in [33-35]. These findings imply 419 that the parameters identified through a proposed approach on a concrete with finer aggregates 420 could be applied to concrete with coarse aggregates using a factor similar to that of Eq. 19. 421 However, this hypothesis is yet to be verified.

\section{3. Applying proposed buildability criteria to CONPrint3D}

423 Generalized buildability criteria proposed above in Section 2 are applied here to an on-site concrete 424 3D-printing technology, CONPrint3D. On completion of this section, the specifications of 425 buildability tests on cementitious materials applicable for CONPrint3D are clearly derived. As elaborated in Section 2, these necessary specifications are: height of the experimental wall to be printed, number of layers in this wall, and the time interval (TI) between the layers. While the target full-scale implementation of CONPrint3D technology will be primarily with coarse-grained aggregates, of maximum aggregate size $8 \mathrm{~mm}$ to $16 \mathrm{~mm}$, the use of fine-grained concrete should not be excluded, certainly not at this stage, since it has many advantages with respect to processing and the maturity of the extrusion machine technology required, "lightness" of the printhead, etc. Thus, as a first step the validation presented below will consider an application case of CONPrint $3 \mathrm{D}$ where fine-grained concrete is used. The reason behind this is that the validation can be performed directly without need for additional assumptions or specific correcting factors. In a follow up study, the proposed buildability criteria will be applied to $8 \mathrm{~mm}$ aggregate, printable concrete, and if necessary adjustment of the approach will be made. Note that the higher material costs of fine-grained concrete are taken into account in Section 3.2.

\section{8}

\subsection{Height of the wall specimen and number of layers to be tested}

439 Of the primary target applications for the CONPrint3D approach, one- to multi-story residential 440 buildings [5,8] make up an important segment; see Figure 5. Table 2 presents the dimensions of the 441 corresponding outer and inner walls for each story. Also presented are the nozzle dimensions 442 employed for the lab-scale 3D-printing testing device (3DPTD), which was designed in 2015 at the 443 TU Dresden and has been used since then for material development. Furthermore, Table 2 presents various extra cases, namely Inner, Outer 2 and Outer3. These cases provide additional information 
445

446

447

448

449

450

451

452

453

454

455

456

457

on how $H_{\text {min,exp }}$ and $n_{\text {layers }}$ vary depending on wall and nozzle dimensions. $H_{\text {min,exp }}$ and $n_{\text {layers }}$ are calculated using Eq. 9 and Eq. 11. These calculations highlight the consideration of layer geometry in the proposed buildability criteria. If the laboratory nozzle breadth is increased and laboratory nozzle height remains unchanged, then the height $H_{\text {min,exp }}$ to be tested in the laboratory also increases. If the thickness of the target wall decreases, as in the case of inner walls, then $H_{\text {min,exp }}$ increases. Similarly, if the height of the printed layer, i.e. nozzle in the lab, increases where its breadth remains unchanged, then the number of layers to be printed in the laboratory tests will decrease. These variations of buildability test specifications are crucial, considering that the nozzle dimensions in the laboratory printers may vary significantly even though the final targeted element (application) dimensions and the geometry of the real-application printhead do not change.

Table 1: Dimensions of the target application and corresponding calculated parameters for laboratory buildability testing.

\begin{tabular}{|c|c|c|c|c|c|c|}
\hline & Parameter & Unit & Outer & Inner & Outer2 & Outer3 \\
\hline \multirow{3}{*}{ 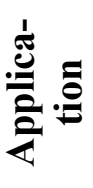 } & Wall height & $\mathrm{m}$ & 2.500 & 2.500 & 3.000 & 2.500 \\
\hline & Wall breadth & $\mathrm{m}$ & 0.240 & 0.175 & 0.240 & 0.240 \\
\hline & Aspect ratio & & 10.417 & 14.286 & 12.500 & 10.417 \\
\hline \multirow{4}{*}{ बิ } & Layer breadth & $\mathrm{m}$ & 0.030 & 0.030 & 0.030 & 0.060 \\
\hline & Layer thickness & $\mathrm{m}$ & 0.020 & 0.020 & 0.020 & 0.020 \\
\hline & Height to be tested & $\mathrm{m}$ & 0.313 & 0.429 & 0.375 & 0.625 \\
\hline & No of layers & \# & 16 & 21 & 19 & 31 \\
\hline
\end{tabular}

458

459

460

461

462

463

464

465
The material explicitly considered in this article is a high-strength, fine-grained concrete $\mathrm{M}$, its compressive strength at an age of 28 days exceeding $80 \mathrm{MPa}$, developed for the outer load-bearing walls of the target residential buildings. Thus, for the laboratory buildability tests, case 'Outer' presented in Table 2 will be considered. Table 2 shows that to ascertain the buildability of the mixture $M, 16$ layers have to printed in the laboratory, complying with maximum time-interval and prescribed tolerances, for example, according to the German standard DIN 18202:2013-04 [26]). The handling of the cases other than Outer should follow the same routine. 


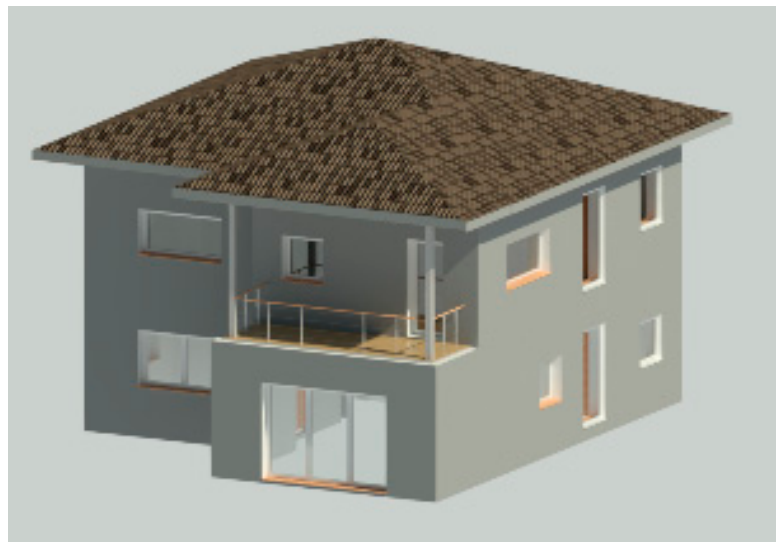

Figure 5: Sketch of a representative target residential building.

\subsection{Time interval (TI)}

The calculations presented below are valid for walls of one floor of a multi-story house erected using CONPrint3D; for purposes of comparison an estimation for walls made of conventional masonry are provided too. The process parameters of masonry construction are given in Table 2; here the use of sand-lime bricks is assumed. These are used to calculate the construction costs for the masonry work and to derive $V_{D C \text {, min }}$.

Table 2: $\quad$ Dimensions of the target application and process parameters of example masonry constructions

\begin{tabular}{|c|c|c|c|c|c|c|}
\hline & Parameter & Unit & Outer & Inner & Outer2 & Outer3 \\
\hline \multirow{3}{*}{ 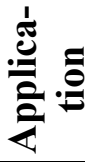 } & Wall height & $\mathrm{m}$ & 2.500 & 2.500 & 3.000 & 2.500 \\
\hline & Wall length & $\mathrm{m}$ & 43.040 & 19.860 & 43.040 & 43.040 \\
\hline & Wall breadth & $\mathrm{m}$ & 0.240 & 0.175 & 0.240 & 0.240 \\
\hline \multirow{5}{*}{ 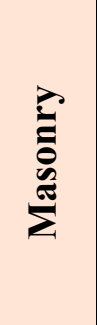 } & $\begin{array}{l}\text { Inversed rate of } \\
\text { construction }\end{array}$ & $\mathrm{h} / \mathrm{m}^{2}$ & 0.6 & 0.6 & 0.6 & 0.6 \\
\hline & Machine costs & $€ / \mathrm{h}$ & 14 & 14 & 14 & 14 \\
\hline & Labor costs per person & $€ / \mathrm{h}$ & 35 & 35 & 35 & 35 \\
\hline & No. of workers & person & 3 & 3 & 3 & 3 \\
\hline & Material costs & $€ / \mathrm{m}^{3}$ & 164.05 & 164.05 & 164.05 & 164.05 \\
\hline
\end{tabular}

The outer wall length of $43.04 \mathrm{~m}$ and the inner wall length of $19.86 \mathrm{~m}$ as presented in Table 2 are calculated from the floor layout of the target application, presented in Figure 6. To calculate the printhead travel length for each layer to be deposited, it is essential to address "printing scenarios" or the aspect of "tool-path optimization". For the sake of simplicity, in the example presented here we assume that one complete layer along the outer walls is printed first. Subsequently, further layers of the outer walls are added upon one another. After the completion of the outer walls, the inner walls are produced and frictionally connected to the outer walls by stainless steel anchors, which are inserted into each layer. In contrast to this simple scenario, the path of the printhead can be defined in numerous ways, as shown in Figure 7, while various algorithms can be utilized for determining the optimum printing scenario. In such cases, the wall length in Table 3, must be adjusted according to the printing path finally chosen. 
485 It is noteworthy that the choice of a suitable starting point and the minimization of idle-traverses 486 (travel times without concrete discharge, shown with the dashed line in Figure 7) are of great 487 importance in any printing strategy.

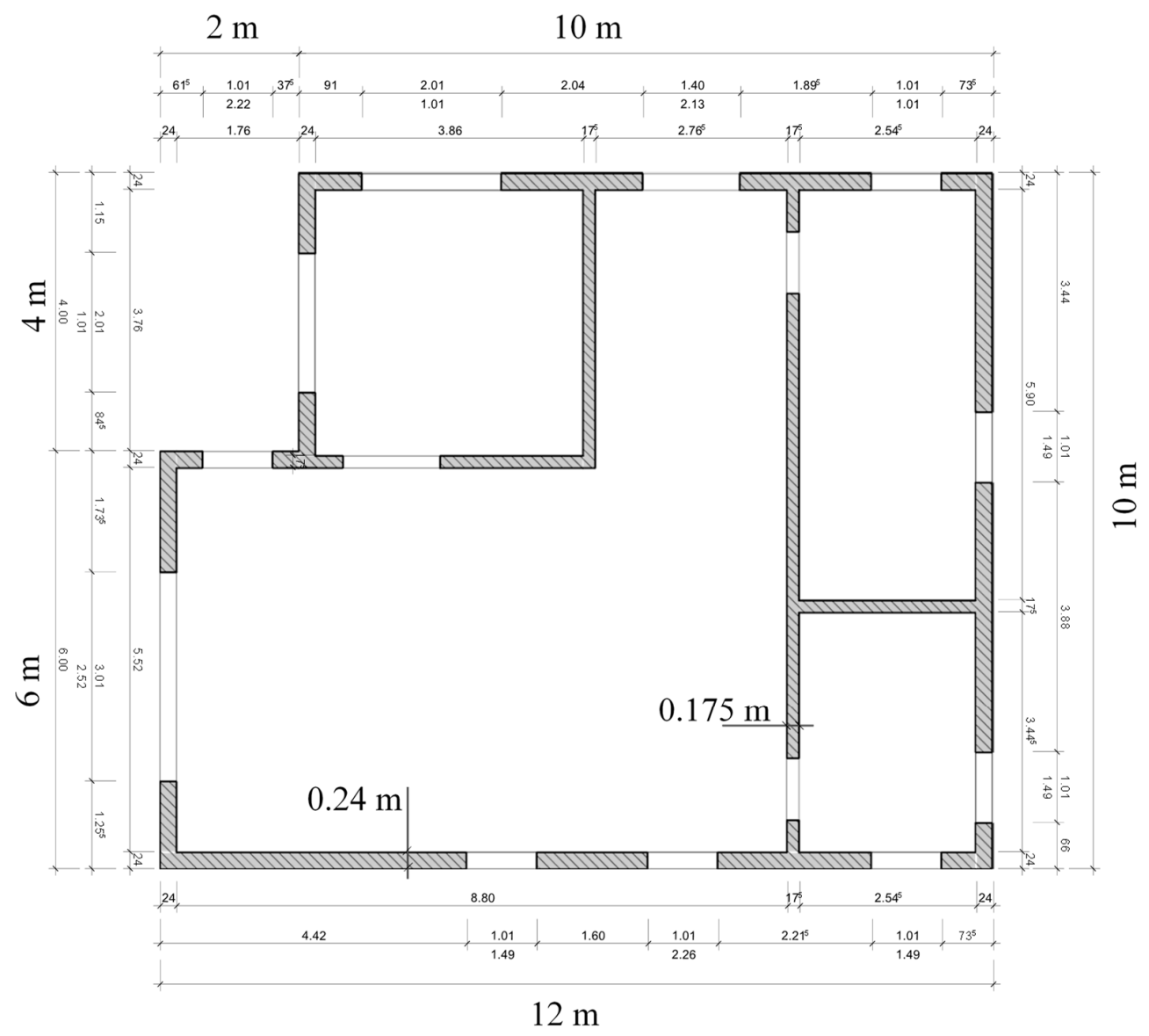

Figure 6: Layout and dimensions of a storey of the target house.

The optimal printing path depends on numerous boundary conditions. An essential optimization criterion is the path length. While the shortest printing path should be generally preferred, it cannot always be used due to other constraints, such as the motion and clearance profiles of the printhead or on-site construction process conditions. Zhang et al. [36] adapted the so-called "traveling salesman problem (TSP)" to determine the optimal tool path for constructing with Contour Crafting technology. They derived the shortest paths by adding multiple vertices in the corners and wall connections, and then by transforming the optimization problem from the node-oriented to the edge-oriented view. 


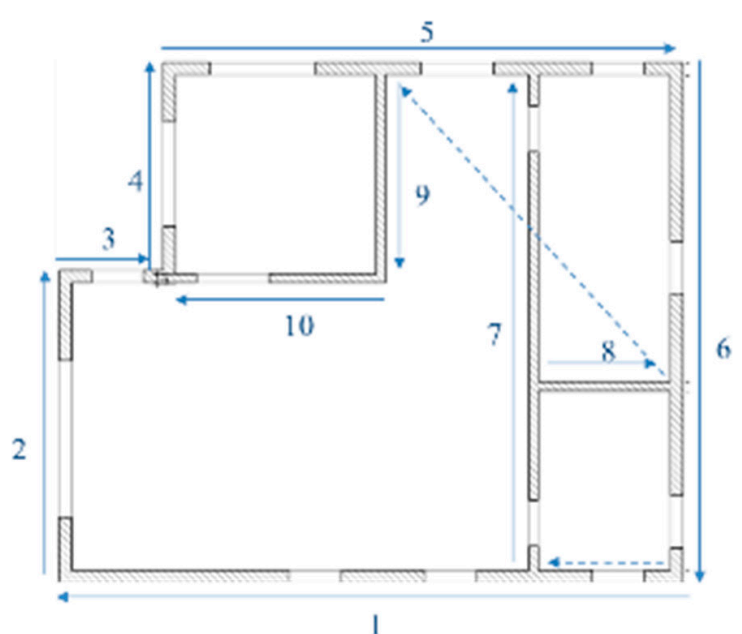

2

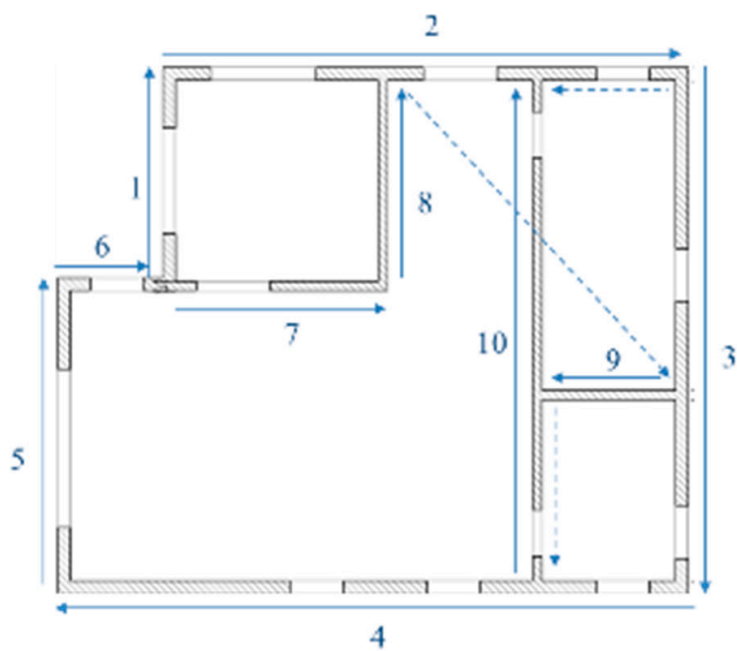

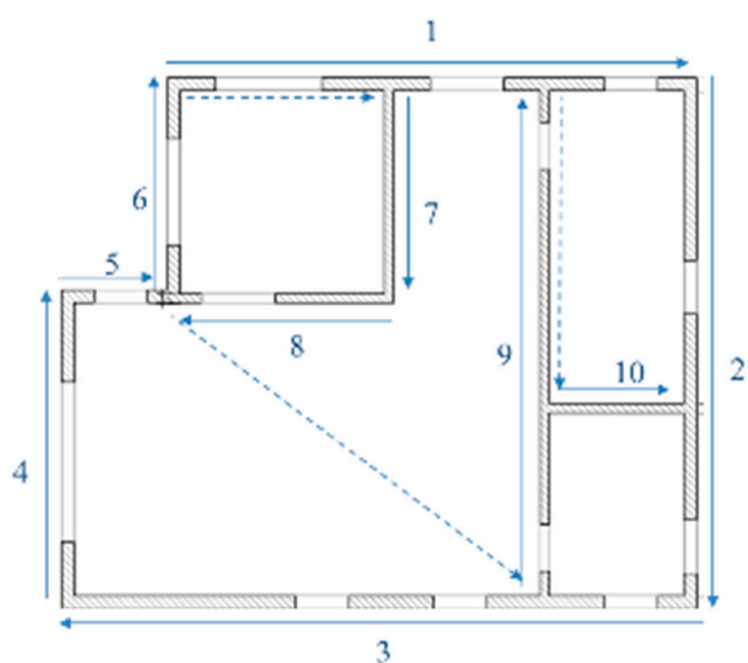

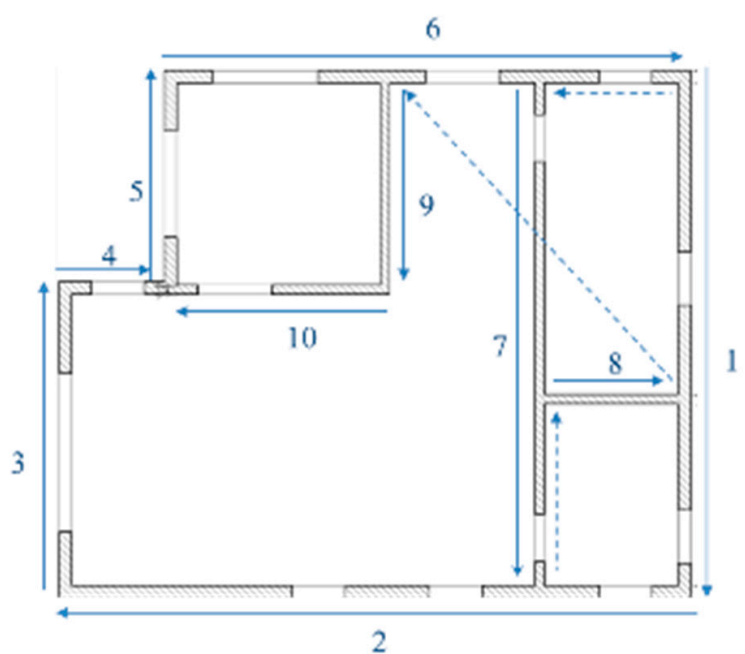

499

Figure 7: Various scenarios for printing the walls of a house considered under consideration.

The rate at which masonry construction takes place is generally expressed in terms of the time needed to complete a square meter of a wall, usually an hour. Since this rate is inverse to the rate generally considered in concrete construction rates, i.e., unit area per unit time, more specifically square meters per hour, it is termed here inversed rate of construction with a notation RI; see Section 2. The RI values used in the articles at hand are according to Baukosteninformationszentrum Deutscher Architektenkammern (BKI) for the masonry wall type KS-L-R 8 DF $240 \mathrm{~mm}$ [37]. The rate of construction is given per person, thus, when deriving $V_{D C}$ using Eq. 17, one must multiply $R I$ with actual number of workers working on the masonry application, which is in this case three, leading to an effective $R I$ of $0.2 \mathrm{~h} / \mathrm{m}^{2}$.

Machine costs presented in Table 4 for a small crane (Kleinkran C.2.00.0007I) are in accordance with BGL 2015 [38]. These costs include repair, depreciation and interest costs. The material costs are also calculated for the masonry wall type Format KS-L-R 8 DF $240 \mathrm{~mm}$ and include delivery and mortar costs [37]. Process parameters of the CONPrint3D are presented in Table 4, which are used to calculate the construction costs and derive $V_{D C \text {, min }}$. 
Table 3: $\quad$ Process parameters for the application of CONPrint $3 D$

\begin{tabular}{|c|c|c|c|c|c|c|}
\hline & Parameter & Unit & Outer & Inner & Outer2 & Outer3 \\
\hline \multirow{5}{*}{ 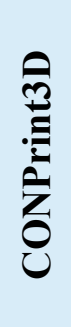 } & Layer thickness & $\mathrm{m}$ & 0.160 & 0.117 & 0.160 & 0.160 \\
\hline & Layer breadth & $\mathrm{m}$ & 0.240 & 0.175 & 0.240 & 0.240 \\
\hline & Machine costs & $€ / h$ & 140 & 140 & 140 & 140 \\
\hline & Labor costs ( 2 persons) & $€ / h$ & 70 & 70 & 70 & 70 \\
\hline & Material costs & $€ / \mathrm{m}^{3}$ & 130 & 130 & 130 & 130 \\
\hline
\end{tabular}

516 Since CONPrint3D is an FWP process, the breadth of the printed layer is equal to the breadth of 517 the target wall. For the case "Outer" considered here, the breadth of a printed layer is $0.24 \mathrm{~m}$. The 518 thickness of the layer is a process parameter which affects the total number of layers to be printed, 519 total printing time, and hence construction costs. The maximum feasible layer thickness depends 520 on the material properties. For the case presented here, layer thickness was assumed to be two521 thirds of the layer breadth in accordance with the geometrical proportions of the nozzle of the lab 522 printer. Numerous scaled-down wall-elements, including those in Figure 4, had been already 523 printed using the aforementioned nozzle-aspect ratio. Machine costs for CONPritn3D as given in 524 Table 4 are, at the current stage, higher than that of masonry construction. They include costs for a 525 modified concrete boom pump, costs for transporting concrete from mixing plant to construction 526 site and costs for adjusting and calibrating the pump on the site. In general, for DC technologies 527 lower manpower costs are envisioned in comparison to conventional construction. In the case of 528 CONPrint3D two workers would be necessary from today's perspective: one for machine 529 monitoring and one for auxiliary works. Based on BKI 2017 values, the average wage of one 530 person is calculated at $35 €$ per hour [37].

531 The material costs for CONPrint3D, $130.00 € / \mathrm{m}^{3}$, are calculated conservatively for high-strength, 532 fine-grained concrete $M$ used in experiments. They include material costs for admixtures and 533 additives (micro-silica suspension, fly ash and superplasticizer). In sum, the material costs are 534 approximately $70 \%$ higher in comparison to the material costs for ordinary concrete of the strength 535 class $\mathrm{C} 25 / 30$ in conventional construction. The mixture $M$, containing expensive additives and 536 admixtures, was chosen deliberately for the calculations to ensure process-safe implementation of 537 the onsite digital construction of load-bearing elements since printable concrete is, in general, likely 538 to contain fine mineral additives and chemical admixtures to achieve the required rheological, 539 mechanical and/or durability characteristics. While for the target residential building application, 540 the required concrete class according to DIN EN 206-1 is C25/30. The fine-grained concrete 541 considered here has a compressive strength of $100 \mathrm{MPa}$ at an age of 28 days. Thus, a considerable 542 reduction in material costs is feasible in the course of the optimization process. In addition to 543 material, machine and labor costs, $10 \%$ additional costs are added to the total costs of CONPritn3D 544 as detailed in Section 2.

545 The minimum average printhead velocity $V_{d c, \min }$ for CONPritn3D application, to be equally 546 economically viable with masonry construction, is calculated using Eq. 17 and data from Tables 2 
through 4. After knowing $V_{d c, \min }$ the maximum (again economically viable) $T I$ between layers can be calculated as $T I=L_{t} / V_{d c, m i n}$. Table 5 presents both $V_{d c, m i n}$ and maximum $T I$ calculated for various cases of CONPrint3D application. For the Outer case, the time interval between extruding subsequent layers should not exceed 51.61 minutes. In addition to the maximum $T I$ it is also possible to define the minimum $T I$ based on the maximum printing speed of the printer to be used. Since the current laboratory printer for CONPrint3D has $V_{d c, \max }=540.00 \mathrm{~m} / \mathrm{h}$, the minimum feasible time interval can be calculated as $T I=L_{t} / V_{d c, \max }$. The minimum $T I$ for the Outer case is 4.78 minutes; see Table 5. It goes without saying that if printing of the entire construction were to occur at a rate close to $V_{d c, \max }$ then the costs and construction time in case of CONPritn3D will be considerably reduced in comparison to those of conventional construction.

Table 4: $\quad$ Process parameters of an example CONPrint $3 D$ application.

\begin{tabular}{|l|l|r|r|r|r|}
\hline Parameter & Unit & Outer & Inner & Outer2 & Outer3 \\
\hline$V_{d c, \text { min }}$ & $\mathrm{m} / \mathrm{h}$ & 50.04 & 72.04 & 50.04 & 100.08 \\
\hline Maximum $T I$ & $\mathrm{~min}$ & 51.61 & 16.54 & 51.61 & 51.61 \\
\hline$V_{d c, \max }$ & $\mathrm{m} / \mathrm{h}$ & 540.00 & 540.00 & 540.00 & 540.00 \\
\hline Minimum $T I$ & $\mathrm{~min}$ & 4.78 & 2.21 & 4.78 & 4.78 \\
\hline
\end{tabular}

558

559

560

561

562

563

564

565

566

\subsection{Experimental validation}

For production of the wall specimens, a custom-developed 3D-concrete-printing test device (3DPTD) was used; see Figure 8 . The 3DPTD is equipped with a progressive cavity pump to extrude concrete. The speed at which a layer is printed and the time interval between the deposition of two consequent layers can be pre-programmed. Details of the mechanical and electrical setup of 3DPTD are to be published elsewhere. The buildability of a fine-grained concrete $M$ was validated using the criteria proposed above. The composition of $M$ can be found in [39]. The target application considered is a residential house; see Section 3.1 and Figure 5. Specifically for the case Outer see Tables 3 to 5 .

Figure 8: Printhead of 3DPTD consisting of concrete hopper, progressive-cavity extruder and nozzle.

569 The design of the buildability experiment is to produce $n_{\text {layers }}$ number of layers with $T I$ minutes 570 of time interval between layers. If the printed wall retains its geometry and dimensions then the 571 tested material is applicable for the target application. As determined in Sections 3.1 and 3.2, a 572 total of 16 layers with maximum time intervals of 61.24 minutes must be printed. The time-interval 
mentioned here is the upper limit. $T I$ longer than 61.24 minutes adversely affects economic viability if all other parameters are assumed constant. At a concrete age of 20 minutes from water addition printing experiments were started by printing layers at a constant velocity of $150 \mathrm{~mm} / \mathrm{s}$ and time intervals of 3 minutes. Figure 9 shows the wall immediately after completion of the printing. Since 16 layers could be printed with a $T I$ much shorter than the economically required $T I$, the mixture $M$ could be designated "buildable" for the considered application case.

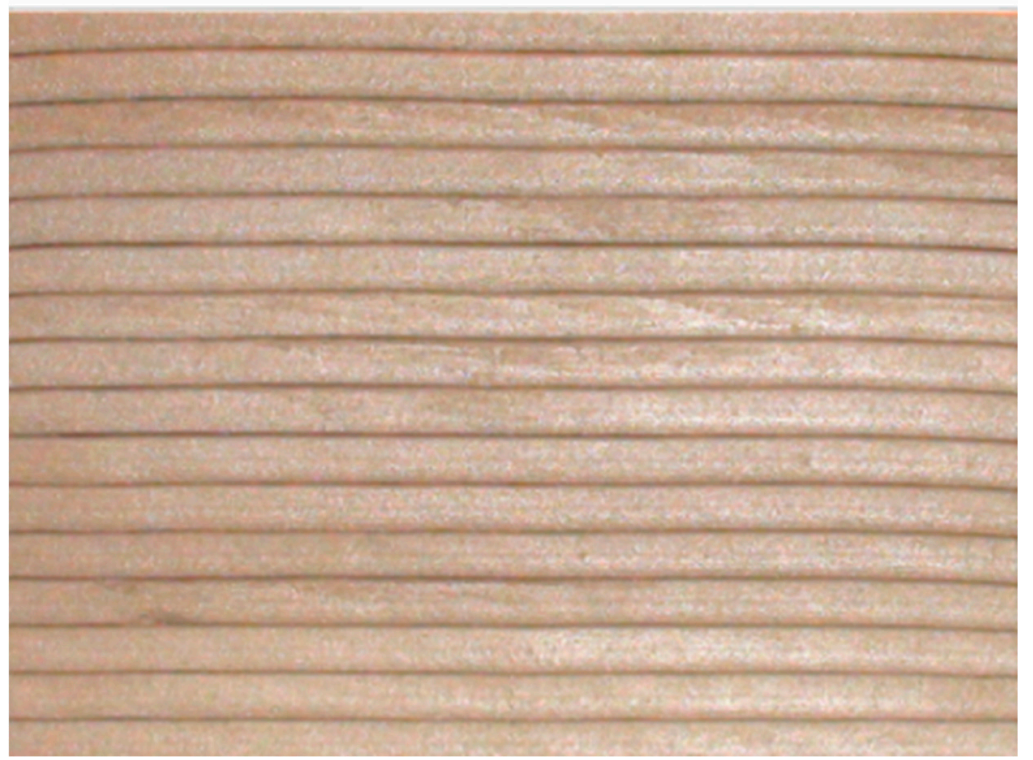

Figure 9: 16-layer wall specimen printed using fine-grained concrete $M$ with time intervals of 3 minutes between layers.

\section{Buildability requirements for filament printing and full-width printing}

Buildability requirements for a material depend not only upon the target structure but also on the printing approach applied. The 'height' component of the buildability criteria remains essentially the same for both the full-width printing (FWP) and filament printing (FP) approaches. In contrast, the 'effective length' of each layer to be printed, i.e. total travel distance, often greater than the length of the actual wall, varies significantly between FWP and FP, which directly affects $T I$ as well. If a single-nozzle opening is used, as in $[2,4,5,10,40]$, in the case of FP, the printhead travels approximately twice the distance in comparison to FWP to complete the deposition of the outer filaments; see Figure 10. Furthermore, additional time is needed to place the inner wave-like filament. Since in the case of full-width printing the entire layer cross-section is printed in one run,

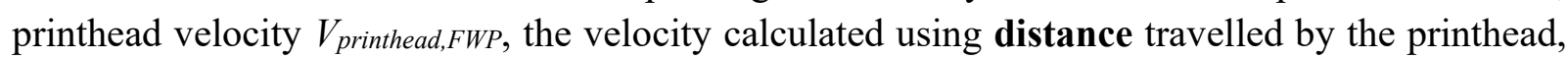
is equal to the "effective" horizontal velocity of printing $V_{\text {effective, } F W P \text {, velocity being calculated }}$ using displacement along the wall length. For FP, in contrast, even if printhead velocity $V_{\text {printhead, } F P}$

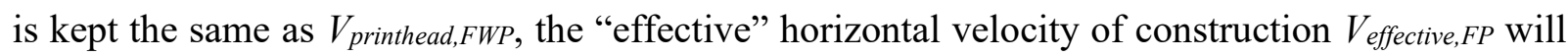

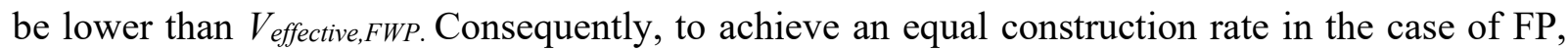
printhead velocity $V_{\text {printhead,FP }}$ has to be much higher than in the case of FWP. A simplistic approximation for FP can be:

$V_{\text {printhead, } F P}=V_{\text {effective, } F P}(2+k)$ with $k=f(\lambda, \hat{u})$

Eq. 20 


\begin{tabular}{|c|c|c|}
\hline & Comparative cases of FP and FWP & FP requires \\
\hline 1 & Constant economic viability & 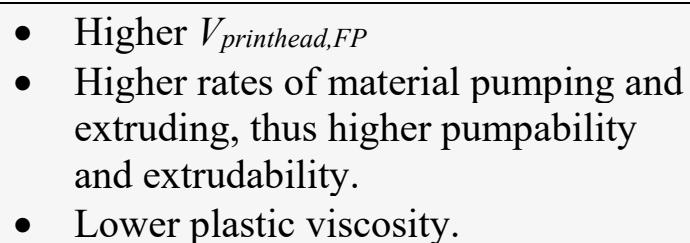 \\
\hline 2 & Constant printhead speed $V_{\text {printhead }}$ & $\begin{array}{l}\text { - Lower buildability ( } T I \text { will be higher) } \\
\text { - higher open-time/working-window of } \\
\text { the construction material } \\
\text { - Longer construction times }\end{array}$ \\
\hline
\end{tabular}

610 It is of interest mathematically to describe the above-mentioned intricacies of buildability

where $\lambda$ is the wavelength and $\hat{u}$ is the amplitude of the wave depicting the inner filament of the wall produced by means of FP; see Figure 10c.

Since the $V_{\text {effective }}$ of FP is much lower than that of FWP the $T I$ between layers in case of FP is also longer. Although it may appear advantageous in terms of "available" resting time for structural build-up, a longer TI means a reduction in the economic viability and a higher risk of formation of "cold joints", weak interface strengths, between layers. Savings in material through FP in comparison to FWP are less significant: as Tables 3 and 4 show, material costs are not the major contributor for the total construction costs.

From a rheological perspective, Eq. 20 implies the following two cases summarized in Table 5, where FP is compared to FWP for the same target application.

Table 5: $\quad$ Requirements in case of FP depending on the comparative constant.

requirements for FP and FWP in order to facilitate:

- Choice between FP and FWP, if the choice of material is restricted;

- Extension of the model presented in Section 2 to FP cases by providing a mathematical description of $T I$ in terms of wall geometry, for instance, the minimum $T I$ in the case of FP be calculated using Eq. 30-32;

- Development of process-agnostic, printable concretes, i.e. concretes applicable for both FP and FWP processes.

The following is the derivation for the needed $V_{\text {printhead, } F P}$ in relation to $V_{\text {printhead,FWP, provided only }}$ one nozzle is used and constant economic viability or constant construction rate is to be achieved (Case 1 in Table 5). 
622

623

624

625

626

627

628

629

630

631

632

633

634

635

\section{Assuming}

- length of the wall to be produced: $L$,

- distances that the printhead travels in case of FWP (Figure 10a): $L 1$,

- distances that printhead travels in case of FP (Figure 10b, -c): $L 2$ for outer and $L 3$ for inner profile,

we obtain:

time for printhead travel in FWP: $t_{F W P}=L 1 / V_{\text {printhead,FWP }}=L 1 / V_{\text {effective, } F W P}$ and

time for printhead travel in FP: $t_{F P}=(L 2+L 2+L 3) / V_{\text {printhead, } F P \text {. }}$

Assuming equal economic viability in FP and FWP as in Case 1 (Table 5), both the times should be equal, thus:

$\frac{L 1}{V_{\text {effective }, F W P}}=\frac{L 2+L 2+L 3}{V_{\text {printhead, } F P}}$

Eq. 21

$V_{\text {printhead }, F P}=\left(\frac{L 2+L 2+L 3}{L 1}\right) V_{\text {effective, } F W P}$

Eq. 22

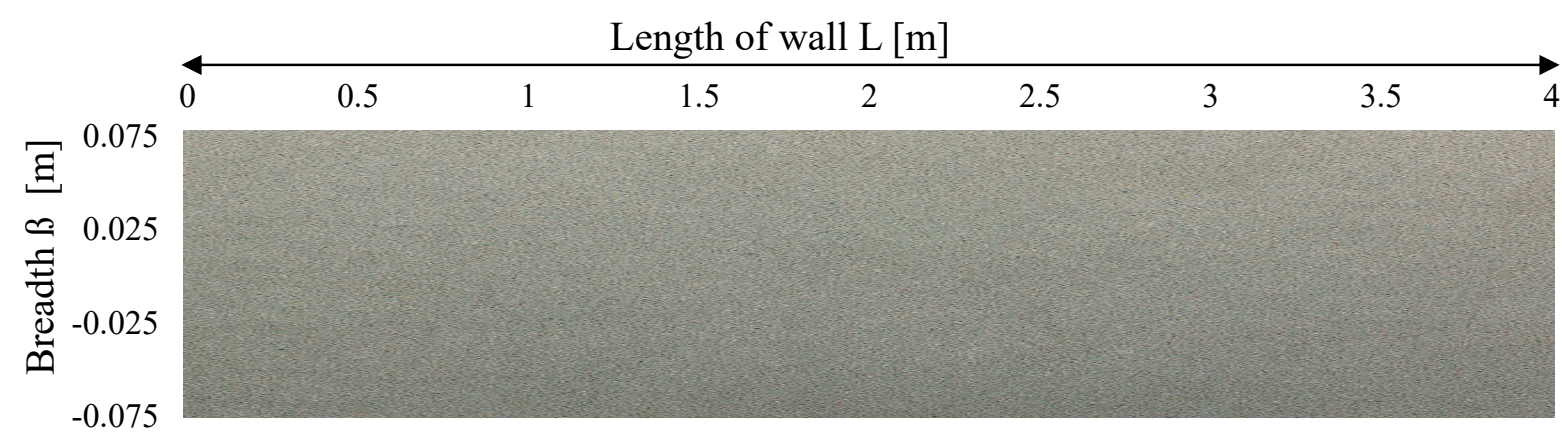

a)

Length of wall L [m]

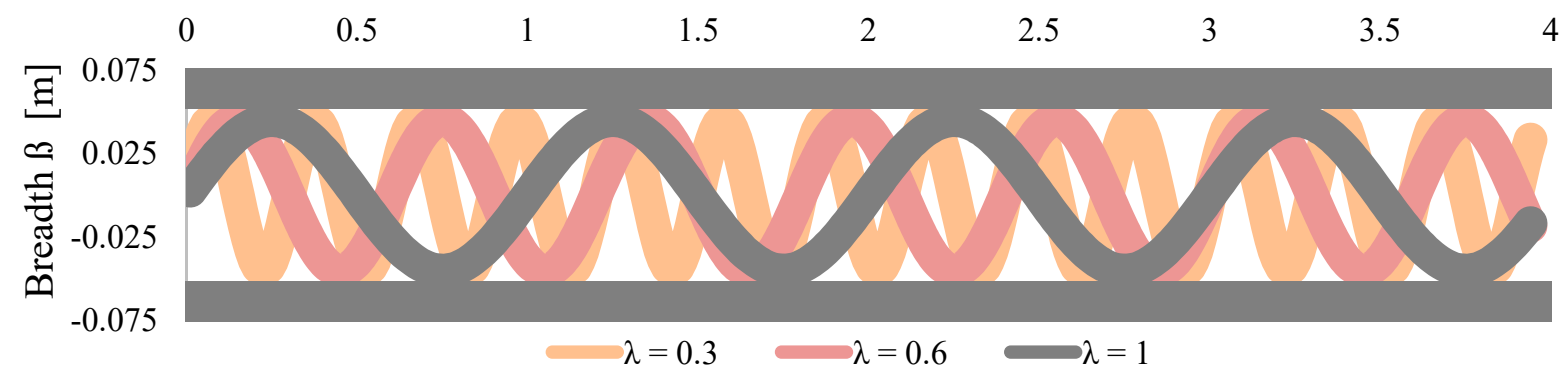

b)

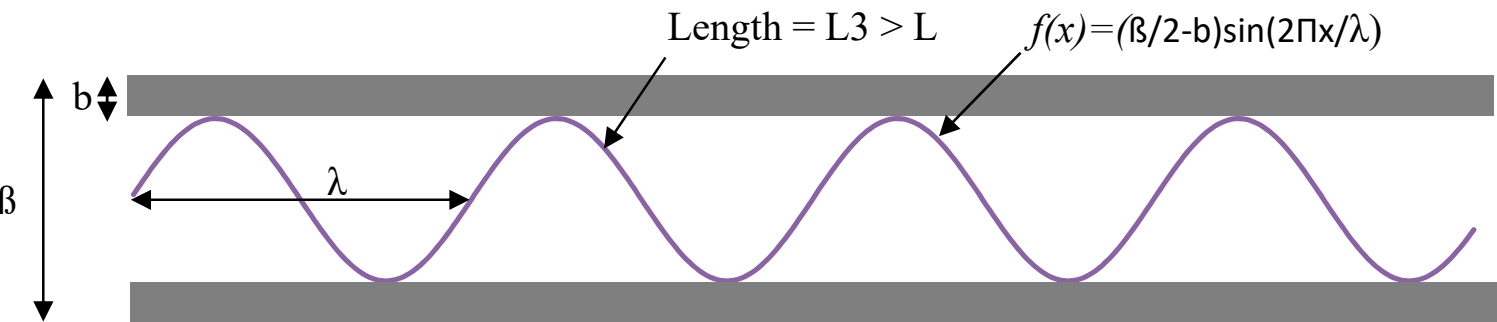

c)

Length $=\mathrm{L}=\mathrm{L} 1=\mathrm{L} 2$

Figure 10: Schematic views of the top sectional views of two walls of identical length and width, produced through a) full-width-printing FWP) and b) filament-printing FP. The FP figure also illustrates two additioanl alternatives 
641 Since the length of the wall $L=L 1=L 2 \neq L 3$

643 Expressing the inner filament in FP as a sinusoid $y=i \sin j x$ from 0 to $L$

644 Length (distance between 0 and $L$ ) of the inner filament is

645

$$
\mathrm{L} 3=\int_{0}^{L} \sqrt{1+\left((i * j) \cos ^{2} j x\right.} d x
$$

Eq. 25

646 With $i=$ semi-amplitude of the inner filament $=\hat{U}=\beta / 2-b$

647 and $j=2 \Pi / \lambda$

648 where $\beta$ and $b$ are the breadth of the produced wall and filament, respectively, and $\lambda$ is the 649 wavelength of the inner filament; see Figure 10c.

650 Length of the inner filament expressed in sinusoid attributes can be calculated according to Eq. 651 26:

$L 3=\int_{0}^{L} \sqrt{1+\left(\left(\frac{\beta}{2}-b\right) * \frac{2 \pi}{\lambda}\right) \cos ^{2} \frac{2 \pi x}{\lambda}} d x$

Eq. 26

653 From Eq. 17 and Eq. 19 we obtain:

$V_{\text {printhead, } F P}=\left(2+\frac{\int_{0}^{L} \sqrt{1+\left(\left(\frac{\beta}{2}-b\right) * \frac{2 \pi}{\lambda}\right) \cos ^{2} \frac{2 \pi x}{\lambda}} d x}{L}\right) V_{\text {effective,FWP }}$

655 Equation 27 enables determination of printhead velocity to be followed while applying FP to retain 656 economic viability equal to that of FWP processes.

657 Still further, if equal economic viability is not the primary concern and constant printhead speed is 658 followed for both FP and FWP, i.e. Case 2 in Table 5, then a higher minimum TI is valid for FP. 659 The following relationship between $T I_{\min , F P}$ and $T I_{\min F W P}$ can be obtained:

$660 T I_{\text {min }, F P}=\left(\frac{\text { Travel length in case of } F P}{\text { Travel length in case of } F W P}\right) T I_{\text {min,FWP }}$ Eq. 28 $T I_{\text {min }, F P}=\left(2+\frac{\int_{0}^{L} \sqrt{\left.1+\left(\frac{\beta}{2}-b\right) * \frac{2 \pi}{\lambda}\right) \cos ^{2} \frac{2 \pi x}{\lambda}} d x}{L}\right) T I_{\min , F W P}$ Eq. 29

662 In addition, with no comparison to FWP, the minimum TI in case of FP can be calculated for a 663 printhead velocity of $V_{\text {printhaed }}$ :

$T I_{\text {min, }, F}=\frac{2 L+\int_{0}^{L} \sqrt{1+\left(\left(\frac{\beta}{2}-b\right) * \frac{2 \pi}{\lambda}\right) \cos ^{2} \frac{2 \pi x}{\lambda}} d x}{V_{\text {printhead }}}$ Eq. 30

665 Eq. 30 is a generalized formula to determine the minimum time intervals between layers, which 666 formula must be followed during laboratory buildability tests if an element of target length $\mathrm{L}$ is 667 produced through FP.

668 It must be noted that Eq. 30 is valid only if one nozzle is used to print the filaments; see Figure 669 11a. If more than one nozzle is used for printing, then the following scenarios can be followed: 
a) Two passes are needed for one horizontal layer of the target wall. In the first pass, two nozzles extrude the outer 'shells' and in the second pass, one nozzle extrudes the inner 'wave'; see Figure 11b. An example of this scenario is demonstrated by Contour Crafting [41].

b) One pass is needed for one horizontal layer of target wall. Two nozzles extrude the outer 'shells' and in parallel, a third nozzle prints the inner 'wave'. To the best of authors' knowledge, this scenario has not yet been demonstrated.

Moreover, in both scenarios one additional pass of the printhead or other devise will be needed if spaces between 'shells' and 'wave' need to be filled, e.g. with insulating materials or (selfcompacting) concrete; see Figure 11c.

For the scenarios 'a' and 'b' mentioned above, Eq. 30 can be transformed to Eq. 31 and Eq. 32, respectively:

$\mathrm{V}_{\text {printhead,FP }}=\left(1+\frac{\int_{0}^{\mathrm{L}} \sqrt{\left.1+\left(\frac{\beta}{2}-\mathrm{b}\right) * \frac{2 \pi}{\lambda}\right) \cos ^{2} \frac{2 \pi \mathrm{x}}{\lambda}} \mathrm{dx}}{\mathrm{L}}\right) \mathrm{V}_{\text {effective,FWP }} \quad$ Eq. 31

$\mathrm{V}_{\text {printhead,FP }}=\left(\frac{\int_{0}^{\mathrm{L}} \sqrt{1+\left(\left(\frac{\beta}{2}-\mathrm{b}\right) * \frac{2 \pi}{\lambda}\right) \cos ^{2} \frac{2 \pi \mathrm{x}}{\lambda}} \mathrm{dx}}{\mathrm{L}}\right) \mathrm{V}_{\text {effective,FWP }} \quad$ Eq. 32

Similarly, Eq. 29 and Eq. 30 can be reformulated according to the number of nozzles used. As can be seen in Eq. 32, even if three nozzles are used and moved at the same speed as in case of FWP, the effective printing velocity in case of FP will be lower in comparison to FWP due to the longer absolute traveling length.

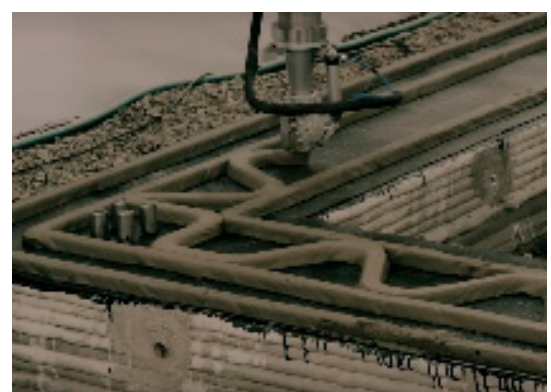

a)

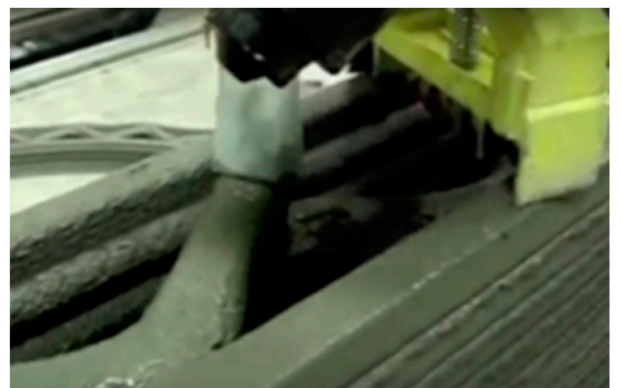

b)

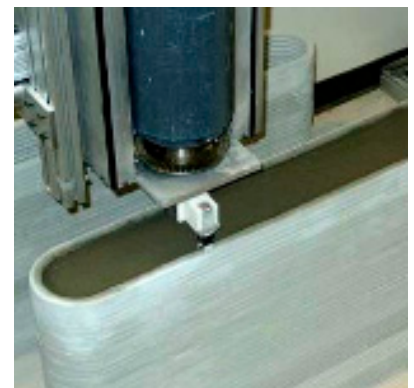

c)

Figure 11: Various scenarios for printing "one set of horizontal layers" in case of FP printing process: a) single nozzle - three passes are needed [42], b) three nozzles - two passes are needed [41] and c) representation of single nozzle with "post-filling" of the empty space between layers [43].

Based on the deduced relationships, it can be concluded that when testing the buildability of a material for FP processes, generally higher velocities of the printhead are to be followed during laboratory tests in comparison to corresponding tests for FWP. 
696

697

698

699

700

701

702

703

704

705

706

707

708

709

710

711

712

713

714

715

716

717

718

719

720

721

722

723

724

725

726

727

728

729

730

731

732

733

734

735

\section{Conclusions and outlook}

Buildability, i.e. the ability of extruded material to retain its shape and size under sustained loads, has been critically examined in the context of digital construction (DC). Practice-oriented buildabiltiy criteria directly linked to their target applications have been proposed herewith. This approach takes machine, labor, and material costs into consideration and so is applicable for quantifying the economic viability of DC processes. The height of the wall to be printed and the time interval between layers were identified as the primary specifications for laboratory buildability tests needed to validate the choice of material and process parameters. The height of the experimental wall was calculated using the aspect ratio of the target construction element. Maximum time interval was determined considering the minimum printing velocity needed for DC to be economically viable in comparison with conventional construction.

In case of CONPrint3D application for a residential building, a lab-scale wall of 16 layers with a maximum time interval of approximately 52 minutes was determined as the buildability test criterion. The buildability of a fine-grained, printable concrete was validated for this application scenario. It was also proven that the buildability criterion for a given material not only depends upon the target structure, but also on the applied printing process/approach. The comparative analyses of full-width printing (FWP) and filament printing (FP) revealed that, assuming the same rate of construction, the buildability of a material for FP processes should be tested at higher velocities of the printhead in corresponding laboratory experiments than in the case of FWP. In addition, a constitutive relationship was derived to calculate the printhead velocity needed in the case of FP related to the velocity in FWP, to achieve an equal construction rate.

Some issues raised in the article at hand are subject of ongoing research. The main activities, actual or planned, can be summarized as follows:

- Validation of the approach with full-scale printing tests, with printable concretes containing aggregates with a maximum size of $8 \mathrm{~mm}$.

Simplification of the proposed approach: A representative piece of wall should be printed in the lab using the same filament geometry as in the real application, however, consisting of a few layers only, while after completion of the printing vertical, stepwise increasing load is applied on this piece. The increase in load should follow the defined time intervals to mimic the deposition of further layers, while measuring deformations. This approach is in principle similar to that proposed by Perrot [20], but different in terms of specimen production (3D-priting instead of casting), geometry and underlying buildability criteria (not based on rheological tests). Most importantly, the question of what a representative piece of the wall to be tested in the lab is and what the time intervals to be tested are to call a material printable can be quantified directly with the approach suggested in the article at hand.

- Direct buildability tests at various ambient conditions (temperature, humidity, wind velocity).

\section{Acknowledgements}

The work presented is a part of the first author's $\mathrm{PhD}$ dissertation. 


\section{References}

[1] B. Khoshnevis, Automated construction by contour crafting-related robotics and information technologies, Autom. Constr. 13 (2004) 5-19.

doi:10.1016/j.autcon.2003.08.012.

[2] R.A. Buswell, R.C. Soar, A.G.F. Gibb, A. Thorpe, Freeform Construction: Mega-scale Rapid Manufacturing for construction, Autom. Constr. 16 (2007) 224-231. doi:10.1016/j.autcon.2006.05.002.

[3] E. Dini, Monolite-UK-Ltd, D-Shape, (2015). https://d-shape.com/ (accessed August 23, 2015).

[4] TotalKustom, 3D-Printed Hotel, (2015). http://www.totalkustom.com/3d-printed-hotelsuite.html (accessed April 27, 2016).

[5] V.N. Nerella, M. Krause, M. Näther, V. Mechtcherine, 3D printing technology for on-site construction, Concr. Plant Int. 4 (2016) 36-41.

[6] C. Gosselin, R. Duballet, P. Roux, N. Gaudillière, J. Dirrenberger, P. Morel, Large-scale 3D printing of ultra-high performance concrete - a new processing route for architects and builders, Mater. Des. 100 (2016) 102-109. doi:10.1016/j.matdes.2016.03.097.

[7] E. Lloret, A.R. Shahab, M. Linus, R.J. Flatt, F. Gramazio, M. Kohler, S. Langenberg, Complex concrete structures - Merging existing casting techniques with digital fabrication, Comput. Des. 60 (2015) 40-49. doi:10.1016/j.cad.2014.02.011.

[8] R. Schach, M. Krause, M. Näther, V.N. Nerella, CONPrint3D: 3D-Concrete-Printing as an Alternative for Masonry, Bauingenieur. 9 (2017) 355-363.

http://www.bauingenieur.de/bauing/article.php?data[article_id] $=88138$ (accessed October $18,2017)$.

[9] D. Weger, D. Lowke, C. Gehlen, 3D printing of concrete structures using the selective binding method - Effect of concrete technology on contour precision and compressive strength, in: 11th Fib Int. PhD Symp. Civ. Eng. FIB 2016, A.A. Balkema Publishers, University of Tokyo, Tokyo, 2016: pp. 403-410.

[10] Mike Murphy, Apis Cor can 3D-print an entire house in just one day, Quartz. (2017) 1. https://qz.com/924909/apis-cor-can-3d-print-and-entire-house-in-just-one-day/ (accessed March 8, 2017).

[11] M. Hansmeyer, B. Dillenburger, Digital Grotesque I, (2014). http://www.michaelhansmeyer.com/projects/digital_grotesque.html?screenSize=1\&color=1\#21.

[12] WinSun, 3D Printing Construction - Project web page, (2015). http://www.yhbm.com/index.php? $\mathrm{m}=$ content\& $\mathrm{c}=\mathrm{index} \& \mathrm{a}=$ lists\&catid=67 (accessed August 23, 2015).

[13] TU Eindhoven, TU Eindhoven starts using kingsize 3D concrete printer, (2015) 3-4. https://www.tue.nl/en/university/news-and-press/news/22-10-2015-tu-eindhoven-startsusing-kingsize-3d-concrete-printer/.

[14] S. Lim, R. Buswell, T. Le, R. Wackrow, S. Austin, A. Gibb, T. Thorpe, Development of a Viable Concrete Printing Process, in: Proc. 28th Int. Symp. Autom. Robot. Constr., Seoul, South Korea, 2011: pp. 665-670. doi:10.22260/ISARC2011/0124. 
[15] T.T. Le, S. A. Austin, S. Lim, R. A. Buswell, A. G.F. Gibb, T. Thorpe, Mix design and fresh properties for high-performance printing concrete, Mater. Struct. 45 (2012) 12211232.

[16] V. Mechtcherine, V.N. Nerella, K. Kasten, Testing pumpability of concrete using Sliding Pipe Rheometer, Constr. Build. Mater. 53 (2014) 312-323. doi:10.1016/j.conbuildmat.2013.11.037.

[17] M. Choi, N. Roussel, Y. Kim, J. Kim, Lubrication layer properties during concrete pumping, Cem. Concr. Res. 45 (2013) 69-78. doi:10.1016/j.cemconres.2012.11.001.

[18] D. Feys, K.H. Khayat, R. Khatib, How do concrete rheology, tribology, flow rate and pipe radius influence pumping pressure?, Cem. Concr. Compos. 66 (2016) 38-46. doi:10.1016/j.cemconcomp.2015.11.002.

[19] T. Wangler, E. Lloret, L. Reiter, N. Hack, F. Gramazio, M. Kohler, M. Bernhard, B. Dillenburger, J. Buchli, N. Roussel, R. Flatt, Digital Concrete: Opportunities and Challenges, RILEM Tech. Lett. 1 (2016) 67-75. doi:10.21809/rilemtechlett.2016.16.

[20] A. Perrot, D. Rangeard, A. Pierre, Structural built-up of cement-based materials used for 3D-printing extrusion techniques, Mater. Struct. 49 (2016) 1213-1220. doi:10.1617/s11527-015-0571-0.

[21] R.J.M. Wolfs, F.P. Bos, T.A.M. Salet, Early age mechanical behaviour of 3D printed concrete: Numerical modelling and experimental testing, Cem. Concr. Res. 106 (2018) 103-116. doi:10.1016/j.cemconres.2018.02.001.

[22] A. Perrot, A. Pierre, S. Vitaloni, V. Picandet, Prediction of lateral form pressure exerted by concrete at low casting rates, Mater. Struct. 48 (2015) 2315-2322. doi:10.1617/s11527014-0313-8.

[23] N. Roussel, A thixotropy model for fresh fluid concretes: theory validation and applications, Cem Concr Res. 36 (2006). doi:10.1016/j.cemconres.2006.05.025.

[24] N. Roussel, C. Lanos, Plastic fluid flow parameters identification using a simple squeezing test, Appl. Rheol. 13 (2003) 132-139.

[25] J. Engmann, C. Servais, A.S. Burbidge, Squeeze flow theory and applications to rheometry: A review, J. Nonnewton. Fluid Mech. 132 (2005) 1-27. doi:10.1016/j.jnnfm.2005.08.007.

[26] Deutsches-Institut-für-Normung-e.-V., DIN 18202:2013-04 - Tolerances in building construction - Buildings, Beuth Verlag, Germany, 2013.

[27] D. Feys, G. De Schutter, K.H. Khayat, R. Verhoeven, Changes in rheology of selfconsolidating concrete induced by pumping, Mater. Struct. 49 (2016) 4657-4677. doi:10.1617/s11527-016-0815-7.

[28] American Concrete Pumping Association, CONCRETE 101 - A guide to understanding the qualities of concrete and how they affect pumping, 2008 .

[29] National Ready Mixed Concrete Association, CIP 21 - Loss of Air Content in Pumped Concrete, 2005. 
[30] A. Perrot, T. Lecompte, P. Estellé, S. Amziane, Structural build-up of rigid fiber reinforced cement-based materials, Mater. Struct. 46 (2013) 1561-1568. doi:10.1617/s11527-0129997-9.

[31] F. Mahaut, S. Mokéddem, X. Chateau, N. Roussel, G. Ovarlez, Effect of coarse particle volume fraction on the yield stress and thixotropy of cementitious materials, Cem. Concr. Res. 38 (2008) 1276-1285. doi:10.1016/j.cemconres.2008.06.001

[32] R.J. Farris, Prediction of the Viscosity of Multimodal Suspensions from Unimodal Viscosity Data, J. Rheol. 12 (1968) 281. doi:10.1122/1.549109.

[33] S.D. Jo, C.K. Park, J.H. Jeong, S.H. Lee, S.H. Kwon, A Computational Approach to Estimating a Lubricating Layer in Concrete Pumping, Comput. Mater. Contin. 27 (2012) 189-210. doi:10.3970/cmc.2011.027.189.

[34] M.S. Choi, Y.J. Kim, J.K. Kim, Prediction of Concrete Pumping Using Various Rheological Models, Int. J. Concr. Struct. Mater. 8 (2014). doi:10.1007/s40069-014-00841.

[35] Federal Statistical Office, Baugenehmigungen im Hochbau 2014, (2015).

[36] J. Zhang, B. Khoshnevis, Optimal machine operation planning for construction by Contour Crafting, Autom. Constr. 29 (2013) 50-67. doi:10.1016/j.autcon.2012.08.006.

[37] BKI Baukosteninformationszentrum Deutscher Architektenkammern GmbH, Baukosteninformationszentrum Deutscher Architektenkammern, Baukosten Gebäude Neubau 2017 - Statistische Kostenkennwerte, 2015.

[38] Hauptverband der Deutschen Bauindustrie, BGL Baugeräteliste 2015 Technischwirtschaftliche Baumaschinendaten, Bauverlag BV GmbH, Gütersloh, 2015.

[39] V.N. Nerella, M. Krause, M. Näther, V. Mechtcherine, Studying printability of fresh concrete for formwork free Concrete on-site 3D Printing technology technology (CONPrint3D), in: Rheol. Messungen an Baustoffen, tredition, Regensburg, 2016: pp. 236-246.

[40] Laura Stampler, Chinese Company WinSun 3D-Printed This 5-Story Apartment Building, (2015). http://time.com/3674557/3d-printed-apartment-building-winsun/ (accessed October $25,2015)$.

[41] Cooper Hewitt, Why Design Now?: Contour Crafting - YouTube, (2010). https://www.youtube.com/watch?v=-yv-IWdSdns (accessed March 14, 2016).

[42] Apis-cor, Apis Cor - construction technology, (2017). http://apiscor.com/en/faq/texnologiya-stroitelstva/ (accessed December 29, 2017).

[43] D. Hwang, B. Khoshnevis, Concrete Wall Fabrication by Contour Crafting, in: ISAR 2004 21st Int. Symp. Autom. Robot. Constr., 2004. doi:10.22260/ISARC2004/0057. 